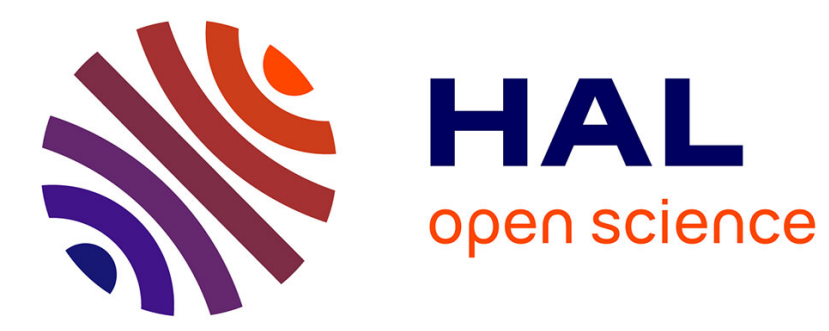

\title{
Model-assisted phenotyping and ideotype design
}

Pierre Martres, Bénédicte Quilot-Turion, Delphine Luquet, Mohamed Memmah, Karine Chenu, Philippe Debaeke

\section{To cite this version:}

Pierre Martres, Bénédicte Quilot-Turion, Delphine Luquet, Mohamed Memmah, Karine Chenu, et al. Model-assisted phenotyping and ideotype design. Crop Physiology, 2ème édition, Elsevier, 2015, 978-0-12-417104-6. 10.1016/b978-0-12-417104-6.00014-5 . hal-01315577

\section{HAL Id: hal-01315577 \\ https://hal.science/hal-01315577}

Submitted on 5 Jun 2020

HAL is a multi-disciplinary open access archive for the deposit and dissemination of scientific research documents, whether they are published or not. The documents may come from teaching and research institutions in France or abroad, or from public or private research centers.
L'archive ouverte pluridisciplinaire HAL, est destinée au dépôt et à la diffusion de documents scientifiques de niveau recherche, publiés ou non, émanant des établissements d'enseignement et de recherche français ou étrangers, des laboratoires publics ou privés. 


\section{Provided for non-commercial research and educational use only. Not for reproduction, distribution or commercial use.}

This chapter was originally published in the book Crop Physiology. The copy attached is provided by Elsevier for the author's benefit and for the benefit of the author's institution, for noncommercial research, and educational use. This includes without limitation use in instruction at your institution, distribution to specific colleagues, and providing a copy to your institution's administrator.

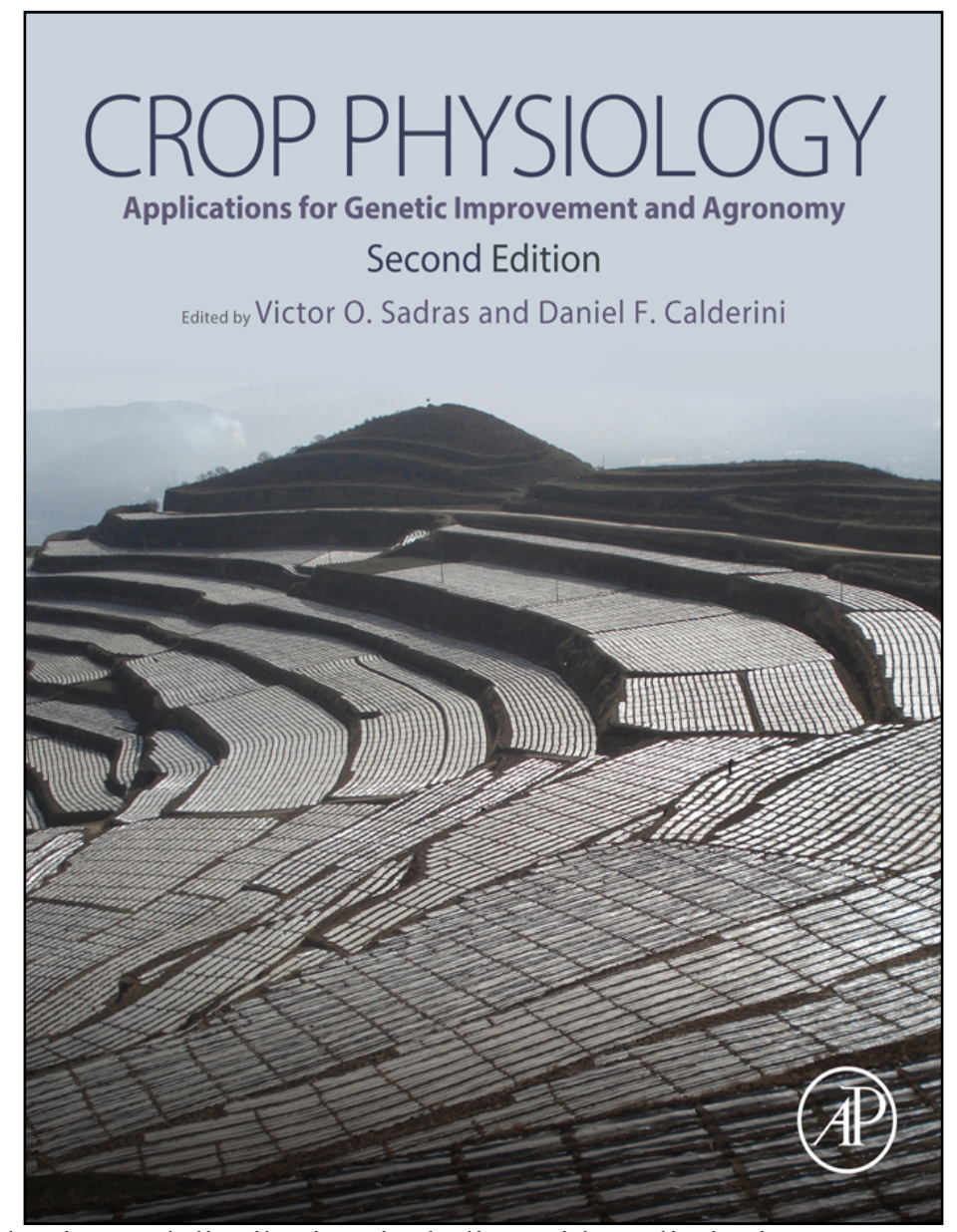

All other uses, reproduction and distribution, including without limitation commercial reprints, selling or licensing copies or access, or posting on open internet sites, your personal or institution's website or repository, are prohibited. For exceptions, permission may be sought for such use through Elsevier's permission site at:

http://www.elsevier.com/locate/permissionusematerial

From Bénédicte Quilot, Model-assisted phenotyping and ideotype design. In: Victor O. Sadras and Daniel Calderini, editors: Crop Physiology, Oxford: Academic Press; 2014, p. 349-374.

ISBN:978-0-12-417104-6

(C) Copyright 2014 Elsevier Inc.

Academic Press. 


\section{H A P T E R}

\section{4}

\section{Model-assisted phenotyping and}

ideotype design

Pierre Martre ${ }^{1,2}$, Bénédicte Quilot-Turion ${ }^{3}$, Delphine Luquet ${ }^{4}$, Mohammed-Mahmoud Ould-Sidi Memmah $^{5}$, Karine Chenu ${ }^{6}$, Philippe Debaeke

${ }^{1}$ INRA, UMR1095 Genetics, Diversity and Ecophysiology of Cereals, ClermontFerrand, France

${ }^{2}$ Blaise Pascal University, UMR1095 Genetics, Diversity and Ecophysiology of Cereals, Aubière, France

${ }^{3}$ INRA, UR1052 Genetics and Improvement of Fruit and Vegetables, Avignon, France

${ }^{4}$ CIRAD, Department of Biological Systems, UMR1334 Genetic Improvement and Adaptation of Mediterranean and Tropical Plants, Montpellier, France

${ }^{5}$ INRA, UR1115, Plantes et Systèmes de Culture Horticoles, Avignon, France

${ }^{6}$ The University of Queensland, Queensland Alliance for Agriculture and Food Innovation, Toowoomba, Queensland, Australia

${ }^{7}$ INRA, UMR1248 Agroécologie, Innovations, Territoires, Castanet-Tolosan, France ${ }^{8}$ INPT, Université Toulouse, UMR1248 Agroécologie, Innovations, Territoires, Toulouse, France

\section{INTRODUCTION}

The whole plant is the central scale of analysis and integration to improve plant population performance (Hammer et al., 2010; Keurentjes et al., 2011; Pedró et al., 2012). This is true from both agronomic and ecological points of view, i.e. regarding production or survival (Dingkuhn et al., 2007). Plant growth results from multiple interactions and trade-offs among processes of various nature (e.g. morphological, physiological, biochemical) acting at different scales (Chapter 1) that can compete for the same resources internally to the plant. These processes can be characterized by traits (Box 14.1) that are potentially linked, both physiologically 


\section{BOX 14.1}

\section{GL O S A R Y}

Emergent property. In system theory, qualifies a higher-level property which is or can be deduced from the properties of the lower level entities.

Genotype. The inherited instructions an organism carried within its genetic code. Not all organisms with the same genotype have the same phenotype because their morphology and physiology are modified by environmental and developmental conditions. Likewise, not all organisms with a similar phenotype have the same genotype. Genotype may refer to the specific allelic composition of the entire genome, and by extension to set of genes, or a specific gene.

$G \times E \times M$ interaction. Indicates that the relative performance of genotypes $(G)$ varies with environmental (E) conditions and with crop management $(\mathrm{M})$. Sometimes $\mathrm{M}$ is included in E. $G \times E(\times M)$ interaction is attributed to the dependence of expression of underlying genes or QTL on environments (QTL $\times$ E interaction). This interaction has often been conceptualized by the following relationship: $G+E+G \times E+$ error (e) $\rightarrow$ Phenotype (P).

High-throughput phenotyping. Plant phenotyping is the experimental assessment of individual quantitative traits (e.g. growth, development, tolerance, resistance, architecture, physiology) that forms the basis for more complex traits. Highthroughput phenotyping involves comprehensive and fast measurements of phenotypes in the lab, the greenhouse or the field. See Chapter 15 for an example.

Ideotype. Combination of morphological and/ or physiological traits, or their genetic bases, optimizing crop performance to a particular biophysical environment, crop management, and end-use.
Multicriteria optimization. Also known as multiobjective or multiattribute optimization. An area of multiple-criteria decision making, which deals with mathematical optimization problems involving simultaneous optimization of multiple objective functions.

Phenotypic plasticity. The ability of a cell, tissue, organ, organism, or species to change its phenotype in response to environmental signals. Induced changes may be morphological or physiological and may or may not be permanent during the lifespan of the considered entity.

Pleiotropy. The phenomenon of a single trait or gene (loci) modifying multiple phenotypic traits that are apparently unrelated.

Quantitative trait loci (QTL). Chromosomal segments (loci) at which the allelic variability is statistically linked to a quantitative trait. QTL may vary depending on the population and the environment studied.

Phenotype. The expression in a particular environment of a specific genotype through its morphology, development, cellular, biochemical or physiological properties.

Phenome. The set of all phenotypes expressed by a cell, tissue, organ, organism, or species.

Phenomics. The study of the phenome and how it is determined by the genotype and the environment, particularly when studied in relation to the set of genes and the non-coding sequences (genomics), transcripts (transcriptomics), proteins (proteomics) or metabolites (metabolomics).

Trait. A distinct variant of a phenotypic property of an organism that may be inherited, be environmentally determined or be a combination of both. 
(Rebolledo et al., 2013) and genetically (ter Steege et al., 2005). Such linkages could result either from human or natural selection (Rebolledo et al., 2013) and are particularly challenging regarding the improvement of the plant system. Key traits for improving performances at the crop level may be viewed as regulatory hubs with pleiotropic (Box 14.1) actions. These linkages and trade-offs make it difficult to decipher phenotype (Box 14.1) construction and improve crop performance in various agro-climatic conditions. This is becoming even more challenging with the increasing complexity of the plant characteristics sought in breeding programs aiming at combining yield and quality (Chapter 17), disease tolerance and agronomic adaptation in current and future climates (Chapter 20), and in multiple purpose crops, such as dual-purpose sorghum (Gutjahr et al., 2013) or wheat (Harrison et al., 2011). There is thus the need to better understand interactions and trade-offs between traits or processes contributing to crop performance and their genetic bases.

By formalizing traits as the result of genotypic and environmental effects and the relations among traits, ecophysiological models provide a platform for integrative analyses of the impact of a combination of traits on whole-plant and crop phenotype (e.g. Hammer et al., 2009; Messina et al., 2009; Bertin et al., 2010). The application of such models in the context of phenotype analyses and ideotyping strongly relies on the use of mathematical tools to quantify the effect of individual traits within a trait network from plant measurements made on various genotypes in a range of environments (Farnsworth and Niklas, 1995; Dingkuhn et al. 2007). Modelassisted phenotyping, where a genotype is characterized by a set of traits, provides a phenotypic fingerprint that can be used to explore trait correlations in a population and ultimately to connect model parameters to genetic information.

Ecophysiological models also provide a platform for quantifying the impact of 'simple' traits (individually, or in interaction with other traits in a trait network) on more integrated traits such as yield, in a range of agro-climatic conditions. While breeders have traditionally favored broad adaptation (i.e. development of genotypes with improved performance across all environments), modeling opens new avenues to develop genotypes specifically adapted to a set of conditions of particular interest such as hostile soils, new cultivation techniques, and future climates. Robust statistical methods for quantitative analyses of model parameter influence (sensitivity) on plant performance have been developed (Saltelli et al., 2000) and were recently used to study ecophysiological models (e.g. Makowski et al., 2006; He et al., 2010). Such methods allow quantifying the influence of 'simple' traits, individually and in combinations, on more complex traits such as yield in different environments. This constitutes a first step toward multicriteria optimization (Box 14.1) of yield, quality, disease tolerance, and resource uses.

The use of ecophysiological models to assist in plant and crop phenotyping, allows quantifying meaningful traits that can hardly be estimated experimentally on a large number of genotypes (e.g. cold requirement, plant state variables such as labile $\mathrm{C} / \mathrm{N}$ concentration), using measurements of plant response variables that can more easily be obtained experimentally. Simulations with the estimated genotypic parameters also allow analyzing the behavior of state variables (e.g. internal pools of carbon) that cannot be quantified experimentally (e.g. Luquet et al., 2012a).

One of the main challenges to progress in this direction is to build ecophysiological models that integrate genetic information associated to specific process(es) and simulate interactions among genetic, physiological and environmental controls to estimate the value of integrated traits (i.e. emergent properties, Box 14.1) in various conditions (e.g. Bertin et al., 2010; Hammer et al., 2010). In this chapter, we argue that ecophysiological models can help breeders and geneticists 'to transition from statistical approaches in analyzing genotype-by-environment 
interactions to a knowledge-based view that emphasizes crop responses to specific environmental factor' as called by Edmeades et al. (2004). After defining the ideotype concept in the framework of ecophysiological modeling, we discuss how ecophysiological models can help identify influential traits in given environments and cropping systems and predicting genotypic variation in different environments. We then review recent studies applying ecophysiological models to design varietal types or virtual genotypes better adapted to given environmentmanagement combinations.

\section{THE IDEOTYPE CONCEPT: ITS USEFULNESS AND LIMITATIONS FOR BREEDING AND VARIETAL CHOICE}

The ideotype approach (also called analytical or physiological trait-based approach) was proposed by Donald (1968) to overcome the limitations of the methods used by breeders, namely 'selection for yield (empirical method)' and 'defect/default elimination'. Although these two empirical methods had been effective for improving disease resistance and grain yield, Donald proposed as an alternative first to define an efficient plant type theoretically, based on our knowledge of crop physiology and then breed for it. He defined an ideotype as 'a biological model which is expected to perform or behave in a predictable manner within a defined environment' (Donald, 1968). This conceptual plant model was supposed 'to yield a greater quantity or quality of grain, oil or other useful product when developed as a cultivar'.

According to this approach, breeders should select directly for the plant ideotype, rather than empirically for grain yield. As several target traits besides final grain yield were provided, concrete guidelines have since been made to conduct the breeding process (Sedgley, 1991; Rasmusson, 1991; Reynolds et al., 2009). For instance, guided by the idea of improving light capture and assimilate partitioning in cereals, Donald identified short stature, strong stem, few small erect leaves, large erect awned ears, low tillering capacity (oligoculm), disease resistance, local adaptation and low plant competitive ability as important target traits for wheat crops sown at high density, under non-limiting conditions. Breeding for such an ideotype has resulted in improved lodging resistance and higher harvest index (Hamblin, 1993).

In the literature, the ideotype concept generally refers to the breeding process, but it can also be extended to the seeking of the best crop phenotype to grow in given environments, with defined cropping systems and for targeted end uses. Commercial varieties can be far from an ideotype viewed as a theoretical objective, the variety choice can be optimized even with a limited range of traits opportunities. Therefore, we suggest broadening the ideotype definition, to the combination of morphological and physiological traits (or their genetic bases) conferring to a crop a satisfying adaptation to a particular biophysical environment, crop management, and end use.

Ideotype breeding was initially developed for annual crops, mainly cereals (Mock and Pearce, 1975; Rasmusson, 1987; Peng et al., 2008; Hanocq et al., 2009) and was later applied to forest and fruit tree species (Dickmann et al., 1994; Socias et al., 1998; Lauri and Costes, 2005; Cilas et al., 2006), emphasizing the generic value of the concept. Since then, the ideotype approach was expanded and refined to include other concerns such as market, new outlets, climate change adaptation (Semenov and Stratonovitch, 2013; Semenov et al., 2014), emerging pests and diseases, and changes in farming system (Jeuffroy et al., 2013). Attempts have also been made to define traits at the biochemical and molecular levels (e.g. Reynolds et al., 1996). Overall, the level of knowledge to support the ideotype approach depends on the crop and final trait (e.g. disease resistant, end-use quality) considered. 
The initial ideotype of Donald was built for low- or non-stress environments where light capture was the major limitation to grain yield. For water-limited environments, the difficulty to design an ideotype is that water deficit affects crop growth and development to a different extent depending on the timing, severity and duration of stress episodes, the history of stresses during the growing season and the interactions between water deficit and other factors such as temperature and nutrient availability. Therefore, it is unlikely that a single trait will improve plant performance in all scenarios of water deficit (Tardieu, 2012). Therefore, specific ideotypes should be conceived for targeted environments. For environments with large inter-annual weather variability, stability of performance is often considered an important varietal characteristic (Braun et al., 1992), but selecting for more specific adaptation could be an alternative (Ceccarelli, 1989). Chapter 13 deals in detail with quantitative environmental characterization in a context of crop adaptation.

While productivity improvement has slowed down in crops like wheat in recent years (e.g. Brisson et al., 2010; Richards et al., 2010), the major benefits of ideotype design are seen as being conceptual and analytical rather than in direct yield improvements (Hamblin, 1993). Progress from using ideotype breeding has often not been as fast as hoped. However, it stimulated interactions among breeders about the utility of the concept and among physiologists, agronomists, breeders and, more recently, modelers about what traits might be important and in which conditions (Marshall, 1991; Hamblin, 1993; Chapman et al., 2003; Foulkes et al., 2011).

Recently, Andrivon et al. (2013) considered three views of ideotypes: (1) the historical, 'genetic' view, as described above; (2) the 'agronomic' view, where new genotypes are designed for specific cropping systems; (3) the 'modeling' view, where the best combinations of traits (usually represented by model parameters) are identified from formal or simulation experiments. They concluded that these views of the ideotype should lead to different breeding strategies. The emergence of new objectives (e.g. low input systems, double purpose crops) and new constraints (e.g. increasing risk of extreme weather events, price volatility) is now arguing for both new breeding objectives and new design methods. Designing crop ideotypes for these new targets is a burning point and no review has recently addressed this subject.

The ideotype design process (ideotyping) could be split into three steps (Fig. 14.1):

1. Definition of the main goal (target) for the breeding process (e.g. breeding for improved water-deficit tolerance)

2. Identification of morpho-physiological traits to reach the defined goal and the way to assemble them within an ideotype (e.g. developing early maturing cultivars or cultivars maintaining photosynthesis under stress or both)

3. Multicriteria assessment of the suggested ideotypes to prove the agronomic relevance of trait integration in target environments (through simulations or field experiments).

Generally, the ideotype is thought of in terms of crop improvement via breeding, but crop management (e.g. sowing density, row width, nitrogen fertilization, irrigation) may also produce the desired ideotypes by exploiting phenotypic plasticity (Box 14.1). For instance, this is the case when dealing with plant architecture traits and crop canopies to limit the epidemic development of pests (Andrivon et al., 2013; Desanlis et al., 2013). So ideotyping may result from breeding and varietal choice but also from crop management and cropping system strategies. While crop management is often added in a second step as an effective driver to complement genetic gains, greatest productivity improvement may arise when combining together both breeding and agronomic practices (e.g. Duvick et al., 2004) (Fig. 14.1). Part 1 of this book presents further examples of the synergy between breeding and agronomy in contrasting cropping systems. 


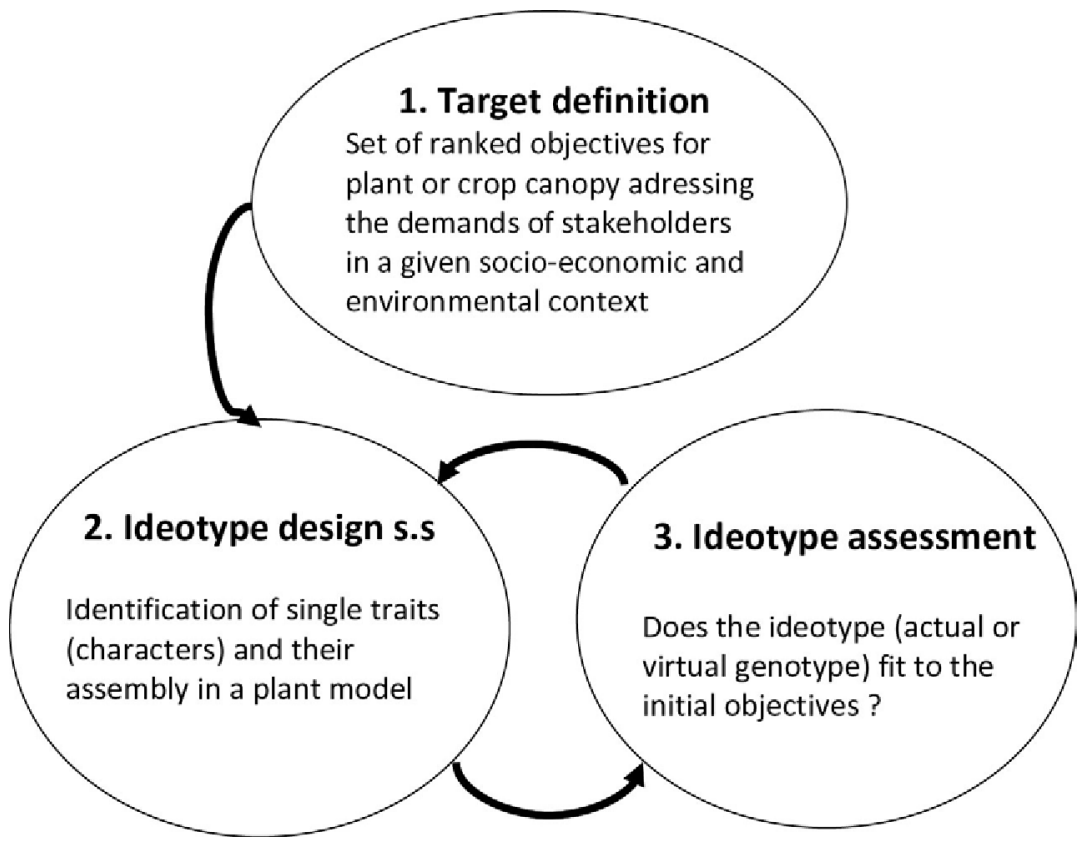

FIG. 14.1 Scheme of the three main steps for ideotype design (ideotyping).

\section{HOW TO DEAL WITH GENETIC CONTROL IN ECOPHYSIOLOGICAL MODELS?}

To support ideotyping, ecophysiological models need to integrate traits that can be reliably estimated based on genetic information. In this section, we present (1) the different levels of complexity found in models concerning the integration of genetic details, with examples on models dealing with quantitative trait loci (QTL)/genes effects; (2) applications of modeling to support trait assessment in multienvironments and to simulate genotype $\times$ environment interactions; (3) the potential of new technologies in this framework and in particular to decipher QTL $\times$ environment interactions; and, finally, (4) the use of integrated models in breeding.

\subsection{Required level of complexity}

White and Hoogenboom (2003) identified six classes of models in relation to genetic detail:
1. Generic model with no reference to species

2. Species-specific model with no reference to cultivars

3. Genetic differences represented by cultivarspecific parameters

4. Genetic differences represented by gene actions modeled through their effects on model parameters

5. Genetic differences represented by genotypes, with gene action explicitly simulated based on knowledge of regulation of gene expression and effects of gene products

6. Genetic differences represented by genotypes, with the gene action simulated at the level of interactions of regulators, gene products, and other metabolites.

Historically, 'generic' (class 1) and 'speciesspecific' (class 2) models were developed first, in the 1970s. Progressively, basic genotypic information has been included, so that most ecophysiological models are now 'cultivar-specific' (class 3 ). Researchers are currently developing 
'gene-specific' models (class 4), which include information from major genes associated to 'simple' traits or from quantitative trait loci (Box 14.1) associated to more complex traits. These models have been proposed for hypothetical genes when key genetic controls were unknown (e.g. Chapman et al., 2003; Hammer et al., 2005) and for genetic controls identified experimentally (Fig. 14.2; Chenu et al., 2009). To date, models based on the 'regulation of gene expression' (class 5) are rare as the understanding of gene action is restricted to particular physiological processes mostly in model species (e.g. Welch et al., 2005; Chew et al., 2012). Despite incomplete information, models of class 5 can be proposed for crop species. For instance, to test physiological assumptions and to improve simulations with the common bean model GeneCro, Hoogenboom and White (2003) introduced an unknown gene (White and Hoogenboom, 1996) which affects the expression of other genes. Lastly, models that simulate gene action based on interactions of regulators, gene products, and other metabolites (class 6) have only been developed for unicellular organisms (Karr et al., 2012; Sanghvi et al., 2013).

Overall, while models of classes 5 and 6 can be relevant for 'simple' traits associated to a restricted number of genes (e.g. flowering time, resistance to a pathogen), more complex traits are usually modeled via QTL (class 4) and/or as emergent properties. The level of detail and complexity of the model (the 'required' complexity) are also defined depending on the targeted applications of the model. Increasing the complexity of a model does not necessary lead to better predictions (e.g. Challinor et al., 2014). Typically, a trade-off between complexity and accuracy has to be addressed to avoid over parameterization (e.g. Reynolds and Acock, 1985) and to limit uncertainty. However, well-known processes that affect traits of interest or key variables of the system might be worth including with further detail in a model. Hence, models typically contain different levels of detail and include submodels of different classes. They evolve with time and may be enhanced by new knowledge focused on central points for predictions.

\subsection{Integration of QTL/genes in ecophysiological models}

Few ecophysiological models include genetic controls (class 4). There, genes or QTL are associated with parameters of the model, and genotypes are defined by a set of parameters which depend on their allelic combination. Robust modeling requires parameters to be constant under a wide range of environmental conditions (Boote et al., 2001; Tardieu, 2003). They often display quantitative and continuous variations in populations, in the same way as variables classically measured (e.g. yield or biomass). However, the QTL associated to these parameters do not systematically co-localize with the QTL for the more integrated variables, thus highlighting the complexity of the system and genetic independence of the trait plasticity and the trait per se. For instance, lack of co-localization was found between QTL for final leaf length of maize under water deficit, and QTL for the parameters associated to leaf expansion response to water deficit (Reymond et al., 2004). Co-localization of QTL for different traits or parameters can nevertheless help better understanding of the processes involved, and thus assist model improvement. For instance, co-localizations between QTL for leaf elongation and anthesis-silking interval in maize suggest that these traits might be regulated by the same underlying process (e.g. tissue elongation for either the leaves or the silks; Fig. 14.2a) (Welcker et al., 2007).

While early work on QTL-based modeling at the crop level has highlighted the need to integrate physiologically-based processes in crops models (e.g. Yin et al., 2000), promising results have since been obtained using physiological components for traits such as leaf elongation (Reymond et al., 2003), plant development (Yin 


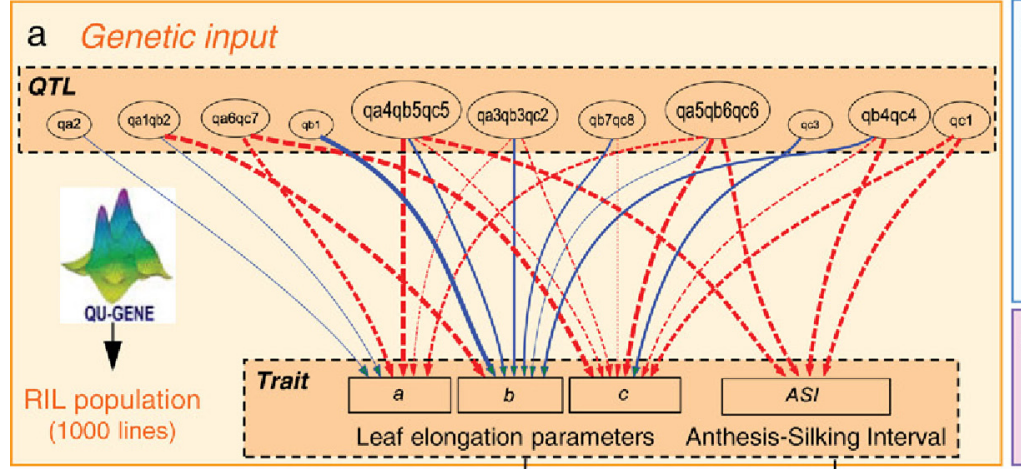

b Environment input (rain, light, temperature)

Soil data

C Management input

Sowing date,

irrigation...

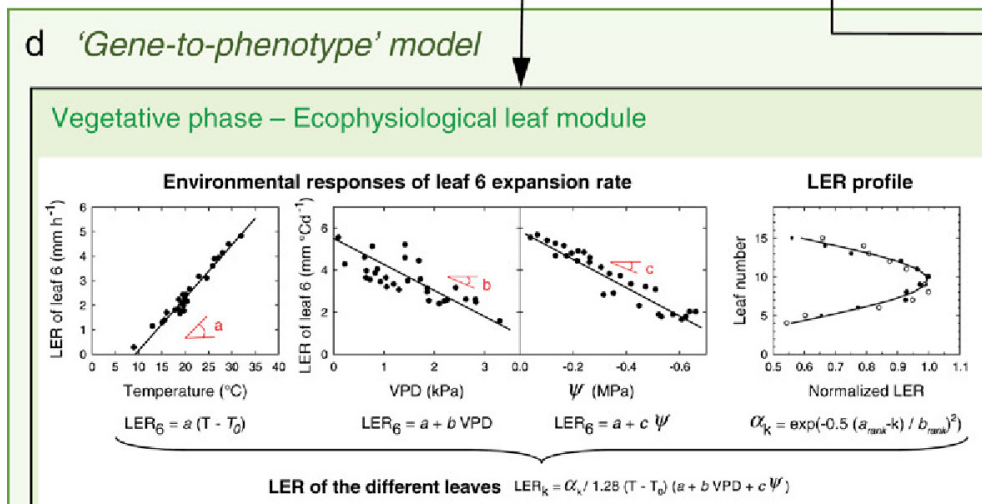

\section{Crop growth, development and water use}

(Interplays of genetics controls, physiological processes and environmental conditions)

e Output

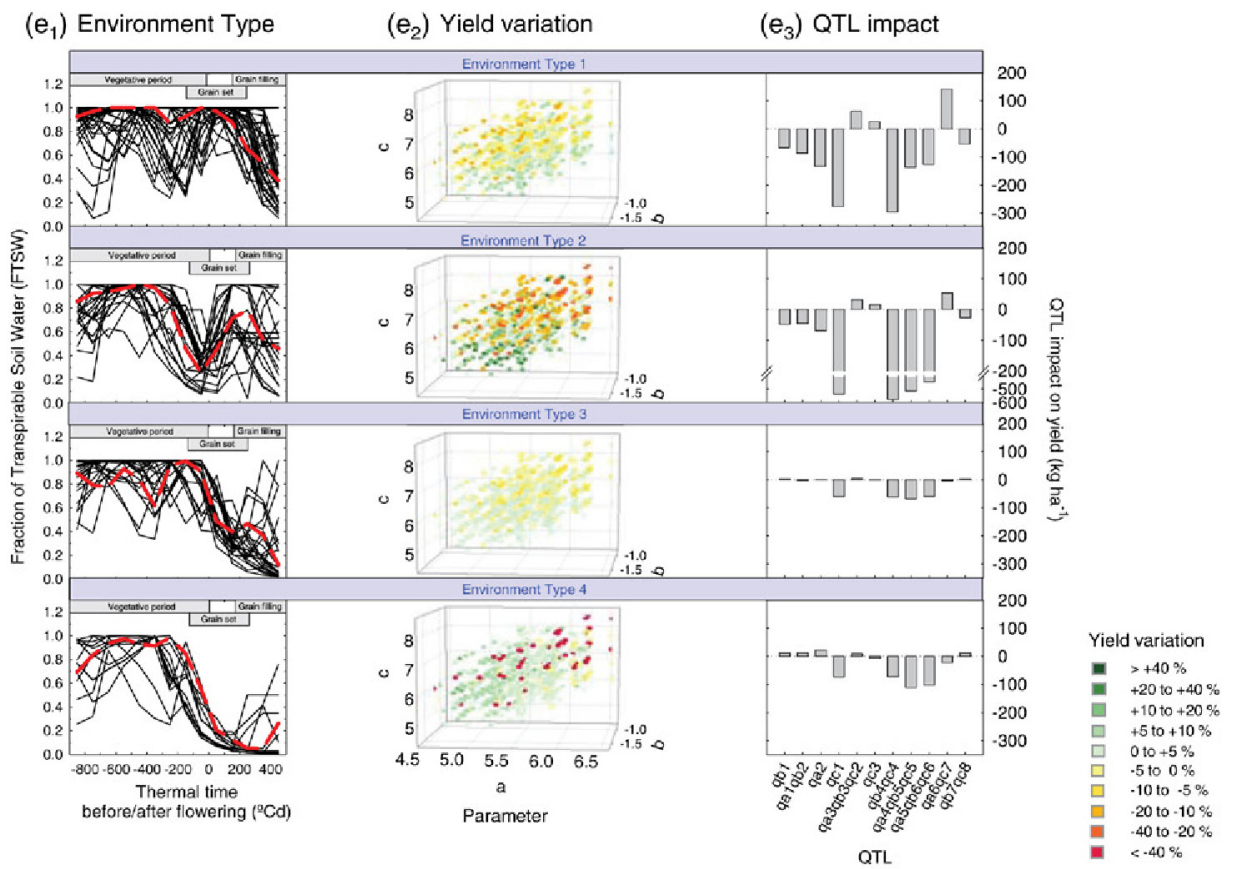


FIG. 14.2 'Gene-to-phenotype' modeling to capture QTL (quantitative trait loci) effects and gene/QTL $\times$ environment interaction from organ to crop levels. Genetic knowledge of 'simple' component traits was used to parameterize the model and to infer the impact of single QTL or QTL combinations on complex traits. In this example, organ-level QTL for leaf and silk elongation of maize were inputs to a modified version of the APSIM ecophysiological model. The impact of the environmentally stable QTL was tested in different environments for 1000 recombinant lines (RILs) simulated with the quantitative genetics model QU-GENE (Podlich and Cooper, 1998) (a). The QTL were associated first with the additive effects (red dashed line, negative; blue solid line, positive) affecting leaf elongation rate (LER) response to temperature (parameter $a$ ), evaporative demand (parameter $b$ ) and soil water deficit (parameter $c$ ) (Reymond et al., 2003), and secondly, with assumed pleiotropic effects on silk elongation and anthesis-silking interval (ASI) under drought (Welcker et al., 2007). These responses were integrated in a leaf module of APSIM, and the response of QTL for ASI was integrated in a reproductive module of APSIM (d). Overall, the model integrated genetic (a), environmental (b) and management (c) information to account for the complex interplay of genetic, physiological and environmental controls throughout the crop cycle (d) (Chenu et al., 2008). After characterizing the drought environment types based on the FTSW (fraction of transpirable soil water) in Sete Laogas, Brazil ( $\mathrm{e}_{1}$ ), simulations were undertaken for four representative drought patterns (red dashed line). Genotype $\times$ environment interaction was generated for simulated yield $\left(\mathrm{e}_{2}\right)$ and the impact of the organ-level QTL highly varied depending on the environment considered $\left(\mathrm{e}_{3}\right)$. For instance, many positive-effect QTL in low / mild stress environments (Environment Types 1 and 2 ) had a negative impact in a severe reproductive stress environment (Environment Types 3 and 4) and vice versa. Two QTL (qa6qc7 and qa4qb5qc5) with similar effects on the LER response to temperature (parameter $a$ ) had contrasting effects on simulated yield $\left(\mathrm{e}_{3}\right)$ (Chenu et al., 2009). Adapted from Chenu et al. $(2008,2009)$.

et al., 2005; Messina et al., 2006), early plant growth (Brunel et al., 2009), nitrogen uptake and root growth and architecture (Laperche et al., 2006) and peach fruit growth and sweetness (Quilot et al., 2005). In each of these studies, QTL associated with the considered traits and processes were identified. Tests of the model against independent data (new genotypes and environmental conditions) were also promising (e.g. Reymond et al., 2003). More details on the approach can be found in recent reviews (e.g. Hammer etal., 2006; Yin and Struik, 2008; Messina et al., 2009; Bertin et al., 2010).

One challenge for ecophysiological modeling is to extend the approach to other component traits. Ideally, complex traits simulated by a model (e.g. yield, fruit quality) should be modeled as emergent properties from component traits, and these component traits should be modeled based on input parameters that are stable across environments and genotype specific.

\subsection{Ecophysiological modeling to support trait assessment in multienvironments}

Estimating parameter values of populations presents a major advantage, as by construction, the parameters are supposed to be independent from the environment and have thus a greater heritability than associated traits. However, a major drawback concerns the observations needed to parameterize the models for a large number of genotypes. First, whole-plant ecophysiological models usually comprise a large number of parameters, typically from 50 to 200 . Second, some parameters are not accessible for measurements, but could represent key traits.

To overcome these difficulties, one possible approach is to identify parameters that have larger impact on the targeted traits (e.g. via a sensitivity analysis of model outputs) or are strongly correlated with such parameters (or their associated traits; Box 14.2). Note that to be of interest, those parameters have to vary among genotypes and be quantifiable with relevant accuracy either experimentally or through numerical optimization. This strategy was applied in the 'Virtual Fruit' model (Génard et al., 2007) in peach and resulted, by successive steps, in reducing the initial set of 39 parameters (Quilot et al., 2005) to 25 parameters inducing significant output variations, from which 16 could be measured in the population studied, and only $10 \mathrm{pa-}$ rameters displayed significant genetic variation. 


\section{BOX 14.2}

\section{IDENTIFYING INFLUENTIAL TRAITS THROUGH GLOBAL SENSITIVITY ANALYSES}

Ecophysiological models can help develop hypotheses starting near the top of the trait hierarchy leading to integrated character such as grain yield and to identify putative influential physiological traits in target environments (Sinclair et al., 2004). Before addressing the question of how to translate the information of model simulations to knowledge that can be used by physiologists or geneticists, we need a better understanding of the model properties and behavior. One of the best ways to do that is to conduct a global uncertainty and sensitivity analysis of the model to investigate its behavior in response to variations in inputs (Cariboni et al., 2007). By perturbing model parameters associated with simple physiological traits, uncertainty and sensitivity analyses allow investigation of crop responses and can help identify those traits that lead to high and stable grain yields in the target environments.

In wheat, and more generally in cereals, maintaining grain protein concentration while increasing grain yield represents a challenge for plant breeders because of the genetic and physiological antagonism between these two characters (e.g. Cooper et al., 2001; Oury et al., 2003; Aguirrezábal et al., 2009). A global sensitivity analysis of the wheat ecophysiological model SirusQuality 2 was conducted with the aim of identifying candidate traits to increase both grain yield and grain protein concentration (He et al., 2010). SiriusQuality2 (http://www1.clermont.inra.fr/ siriusquality) accounts for canopy development, and capture and allocation of $\mathrm{C}$ and $\mathrm{N}$ at the organ and phytomer levels (Martre et al., 2006; Ferrise et al., 2010). Chapter 17 presents further detail of these applications of ecophysiological models to questions of grain quality, and qualityyield trade-offs.
Three contrasting European sites were considered and simulations were performed using long-term weather data and two nitrogen treatments to quantify the effect of parameter uncertainty on grain yield and protein concentration under variable environments. The overall influence of all of the 75 crop parameters of SiriusQuality2 on grain yield and protein concentration was first analyzed using the semiquantitative Morris method (Morris et al., 1991). Forty-one influential parameters with respect to grain yield and protein concentration were identified and their individual (first-order) and total effects on the model outputs were investigated using the extended Fourier amplitude sensitivity test (EFAST; Saltelli et al., 1999).

The Morris analysis showed that most influential parameters are also involved in curvature or interaction effects (He et al., 2010). In other words, the 'overall' importance of a model parameter is primarily determined by the non-linear response of the model or by its interactions with other model parameters. This result was confirmed by the E-FAST analysis, where 8 to $56 \%$ of the variance for grain yield and protein concentration was accounted for by the interactions between the parameters and the overall effect of most individual parameters was dominated by their interactions with other parameters (Fig. 14.3). Interestingly, the contribution of the interactions was twofold higher under low $\mathrm{N}$ (averaging 34\%) than under high $\mathrm{N}$ (averaging $16 \%)$ supply. This result indicates that the expression of the effect of a trait at the crop level depends on the value of the other traits, but also on crop management. The direct implication of this result for plant breeding is that we need to select for combinations of traits (ideotypes), rather than for a single trait. 


\section{BOX 14.2 (cont.)}

When the total sensitivity index (first-order effect plus interaction effects) of the parameters is considered, for each site/ $\mathrm{N}$ supply/model output, $90 \%$ of the sum the total sensitivity index was accounted for by only 6 to 17 parameters (Fig. 14.3). The low number of influential parameters with respect to grain yield and protein concentration may reflect the many compensatory effects between traits (e.g. grain size vs grain number, or light saturated photosynthesis vs leaf surface area) and the fact that complex characters such as grain yield and protein concentration are inherently determined at the population level rather than at the organ or plant level (Sinclair et al., 2004).

Under non-limiting N supply a few influential parameters with respect to grain yield could be identified (e.g. radiation-use efficiency, potential duration of grain filling or phyllochron); however, under limiting $\mathrm{N}$ more than 10 parameters showed equivalent and small effects. All the parameters had opposite effects on grain yield and protein concentration, but leaf and stem $\mathrm{N}$ storage capacity appeared as good candidates to shift the negative relationship between grain yield and protein concentration. These results are consistent with both a previous sensitivity analysis of Siriusquality1 (Martre et al., 2007), and experimental results (Shearman et al., 2005; Gaju et al., 2014). Therefore, grain yield and protein concentration are influenced by several traits and processes and the ranking of the influential traits with respect to grain yield and grain protein concentration depends both on the environment and $\mathrm{N}$ supply.
Another approach consists of estimating the parameters of interest by a global calibration of the model. For example, in rice, the four parameters of the EcoMeristem model that had the most effect on simulation outputs were calibrated in more than 200 genotypes using a hybrid optimization approach (Box 14.3; Luquet et al., 2012b). The other model parameters were fixed at ricespecific values, either because they are known to have low variation or because their variation has low impact on simulated growth.

\subsection{Robust simulation of genotype $\times$ environment interactions}

The foremost expectation of ecophysiological models is the simulation of genotypic variation in different environments and to capture $\mathrm{G} \times \mathrm{E} \times \mathrm{M}$ interactions (Box 14.1) (Asseng et al., 2002; Boote et al., 2003; Chapman et al., 2003; Hoogenboom and White, 2003). However, despite promising results from the work mentioned above, three main shortcomings remain.

First, shortcomings related to the proper characterization of the environment (Chapter 13). The record of climatic inputs and soil parameters is crucial to (1) classify the environments experienced by crops and (2) identify and quantify the main environmental factors affecting genotypic expression of traits of interest. To study the response of specific traits in detail, high-throughput phenotyping platforms have recently been established in greenhouses or in the field, allowing fine environmental monitoring (e.g. Granier et al., 2006; Furbank and Tester, 2011). Furthermore, progress is being made in the phenotyping of physiologically meaningful, yield-related traits that are relevant to breeding (Chapter 15).

Second, shortcomings concerning ecophysiological models themselves and the prediction of $G \times E$ interactions under a wide range of conditions. Typically, models must be improved to 


\section{$1^{\text {st }}$ order sensitivity index for yield}
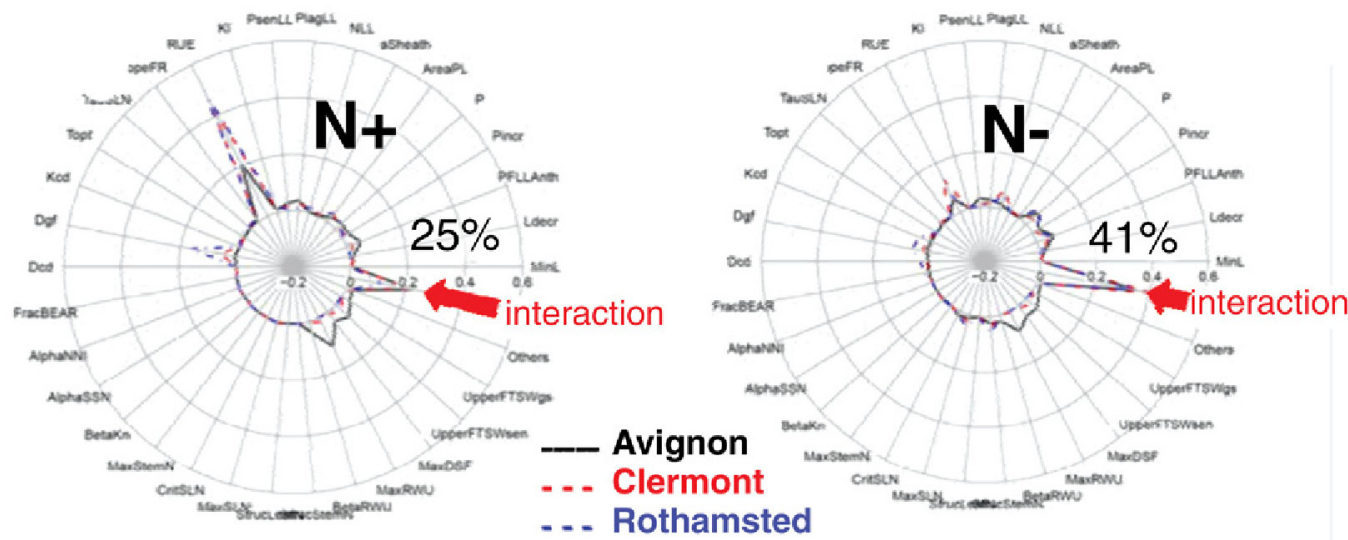

Total sensitivity index for grain protein Total sensitivity index for yield
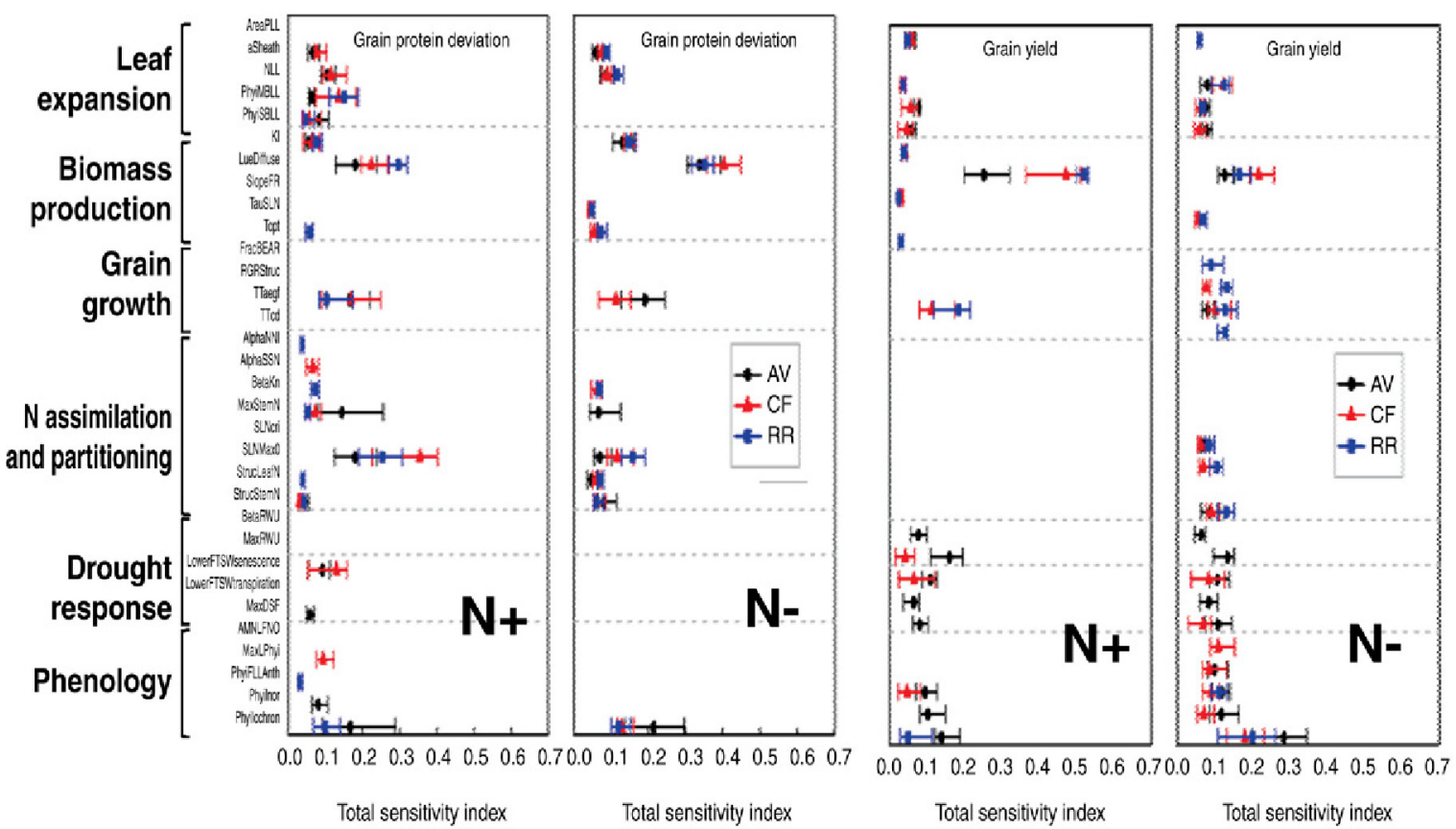
FIG. 14.3 Global sensitivity analysis of the 41 most influential parameters of the wheat ecophysiological SiriusQuality2 calculated at three sites in France and the UK for 40 years of weather data (1970-2009) and with high (N+) and low (N-) nitrogen supply. A parameter is considered as influential with respect to a given trait if its sensitivity index is $>0.1$ for that trait (i.e. if it explains more than $10 \%$ of the variance for that trait due the global parameter perturbation). Top graphs, radar plots of the median values of the extended Fourier amplitude sensitivity test (E-FAST) first-order sensitivity index $\left(S_{\mathrm{i}}\right)$. Bottom graphs, medians of the E-FAST total sensitivity index $\left(S_{\mathrm{Ti}}\right)$. Parameters are grouped according to the submodels (processes) to which they belong (indicated on the left of the graphs). The error bars represent the $25 \%$ and $75 \%$ percentiles. AV, Avignon, France; CF, Clermont-Ferrand, France; RR, Harpenden, UK. For each site, N treatment, and response variable, only the parameters contributing to $90 \%$ of the sum of the total sensitivity index in at least $50 \%$ of the years are shown. In the top graphs, 'Others' indicates $S_{\mathrm{i}}$ contributed by the rest of 9 parameters not represented, and 'Interactions' indicates the total sensitivity index contributed by interactions involving the 41 parameters. Parameters are: AreaPLL $\left(\mathrm{cm}^{2}\right.$ lamina $\left.^{-1}\right)$, maximum potential surface area of the penultimate leaf lamina; aSheath (dimensionless), constant of the quadratic function relating the surface area of leaf sheath between two successive ligules and leaf rank after floral initiation; NLL (number of leaf), number of leaves produced after floral initiation; PhyllMBLL (dimensionless), potential phyllochronic duration between end of expansion and beginning of senescence for the leaves produced after floral initiation; PhylSBLL (dimensionless), potential phyllochronic duration between end of expansion and beginning of senescence for the leaves produced before floral initiation; $\mathbf{K} 1$ ( $\mathrm{m}^{2}$ ( $\mathrm{ground}$ ) $\mathrm{m}^{-2}$ (leaf)), light extinction coefficient; LueDiffuse ( $\left.(\mathrm{DM}) \mathrm{MJ}^{-1}\right)$, potential radiation-use efficiency (RUE) under overcast conditions; SlopeFR (dimensionless), slope of the relationship between RUE and the ratio of diffuse to total solar radiation; TauSLN ( $\mathrm{m}^{2}$ (leaf) $\left.\mathrm{g}^{-1}(\mathrm{~N})\right)$, relative rate of increase of RUE with specific leaf nitrogen; Topt $\left({ }^{\circ} \mathrm{C}\right)$, optimal temperature for RUE; FracBEAR (grain $\mathrm{g}^{-1}(\mathrm{DM})$ ), ratio of grain number to ear dry matter at anthesis; RGRStruc $\left(\left({ }^{\circ} \mathrm{Cday}\right)^{-1}\right)$, relative rate of accumulation of grain structural dry mass; TTaegf ( $\left.{ }^{\circ} \mathrm{Cday}\right)$, grain-filling duration (from anthesis to physiological maturity); TTcd ( $\left.{ }^{\circ} \mathrm{Cday}\right)$, duration of the endosperm cell division phase; AlphaNNI $\left(\mathrm{g}(\mathrm{N}) \mathrm{g}^{-1}(\mathrm{DM})\right)$, scaling coefficient of the $\mathrm{N}$ dilution curve; AlphaSSN ( $\left.(\mathrm{N}) \mathrm{m}^{-2}\right)$, scaling coefficient of the allometric relation between area-based:lamina and sheath $\mathrm{N}$ content; BetaKn (dimensionless), scaling exponent of the relationship between the ratio of nitrogen to light extinction coefficients and the nitrogen nutrition index; MaxStemN $\left(\mathrm{g}(\mathrm{N}) \mathrm{m}^{-2}\right)$, maximum potential stem $\mathrm{N}$ concentration; SLNcri $\left(\mathrm{g}(\mathrm{N}) \mathrm{m}^{-2}(\mathrm{leaf})\right)$, critical area-based nitrogen content for leaf expansion; SLNmax0 ( $\mathrm{g}(\mathrm{N}) \mathrm{m}^{-2}$ (leaf)), maximum potential specific leaf $\mathrm{N}$ of the top leaf layer; StrucLeafN ( $\left.(\mathrm{N}) \mathrm{g}^{-1}(\mathrm{DM})\right)$, structural N concentration of the leaves; StrucStemN (m (N) g $\mathrm{g}^{-1}(\mathrm{DM})$ ), structural $\mathrm{N}$ concentration of the true stem; BetaRWU (dimensionless), efficiency of the root system to extract water through the vertical soil profile; MaxRWU $\left(\mathrm{d}^{-1}\right)$, maximum relative rate of root water uptake from the top soil layer; LowerFTSWsenescence (dimensionless), fraction of transpirable soil water value for which DSFmax is reached; LowerFTSWtranspiration (dimensionless), fraction of transpirable soil water for which the stomatal conductance equals zero; MaxDSF (dimensionless), maximum rate of acceleration of leaf senescence in response to soil water deficit; AMNLFNO (number of leaf), absolute minimum possible leaf number; MaxLPhyll (number of leaf), leaf number above which P is increased by PhyllIncr; PhyllFLLAnth (dimensionless), phyllochronic duration of the period between flag leaf ligule appearance and anthesis; PhyllIncr (dimensionless), factor increasing the phyllochron for leaf number higher than PhyllIncr; Phyllochron $\left({ }^{\circ} \mathrm{Cday}\right.$ leaf $\left.{ }^{-1}\right)$, phyllochron.

(1) simulate phenotypic plasticity for key traits and trait combinations (Dingkuhn et al., 2005; Hammer et al., 2005) in a wide range of environments (Rötter et al., 2011; Lobell et al., 2012; Asseng et al., 2013); and (2) give a representative description of physiological processes and be mechanistic enough to bridge the gap between complex traits and genes. This implies that models must account for interconnections and feedback regulations among subsystem components (e.g. organs or tissues), biological processes (e.g. photosynthesis or protein synthesis) and with the environment (e.g. see review by Bertin et al., 2010). While progress is made in this direction, we are still far from understanding all these interactions.

Third, shortcomings related to the characterization of the genetic controls: (1) parameters are not always directly measureable (e.g. root characteristics in a 'natural' environment); (2) quantifying the genetic parameters for a large number of genotypes remains limiting; (3) conventional QTL analyses are typically performed in biparental populations, which tremendously restricts the genetic variation explored, and the analyses rely on the recombination events taking 


\section{BOX 14.3}

\section{MODEL-ASSISTED PHENOTYPING}

The ecophysiological model EcoMeristem (Luquet et al., 2006) aims at simulating plant morphogenesis in crop stands and its phenotypic plasticity, in terms of leaf size, appearance, growth and senescence rates and tillering, depending on genotypic and environmental characteristics. Genotypes are defined by sets of parameters of equations formalizing morphogenetic (organ appearance rate, dimensioning at initiation time, expansion, and tillering), physiological processes (light interception and conversion efficiencies) and their regulation by plant state variables defined as the ratio between plant supply and demand for water and carbohydrates that result from genotypic characteristics and environmental conditions. The model was validated in its capacity to represent rice phenotypic plasticity and diversity for the above mentioned morphogenetic processes underling rice early vigor. To evaluate the genetic variability of parameters controlling rice early vigor in EcoMeristem and their responses to drought, the model was calibrated for 200 accessions of an Oryza sativa L. ssp. Japonica diversity panel grown in a greenhouse (Luquet et al., 2012).

Nine parameters (Fig. 14.4) were calibrated using the $\mathrm{R}$ package Genoud (Sekhon and Mebane, 2011) to minimize model error for shoot dry mass, surface area of the youngest expanded leaf, leaf and tiller number at the onset and end of a dry down period applied at leaf 6 stage on the main stem until the fraction of transpirable soil water (FTSW) reached a value of 0.2. Inputs were daily weather (incident global radiation, air temperature, potential evapotranspiration), soil volume, and soil drained upper limit and crop lower limit. Parameters were calibrated for three independent experiments.

Most of the calibrated parameters strongly discriminated among genotypes in terms of early vigor and response to drought. However, drought response parameters showed much less heritability compared to morphogenetic, constitutive parameters. Based on correlation and PCA (Fig. 14.4), parameters clustered the collection of accessions in three groups: vigorous but with low drought tolerance; low vigor and good drought tolerance, and a group of intermediate genotypes. This clustering was consistent with that performed based on morphogenetic and metabolic measurements on a subpanel of 50 genotypes of the same collection (Rebolledo et al., 2012). Therefore, this approach confirmed that early vigor and drought tolerance are physiologically linked, but also possibly genetically (negatively), which may have implications when selecting for both traits.

The ranges of parameter values explored accordingly can be considered as representative of existing genetic diversity for the studied species. This information can be used for genome-wide association studies, to explore trait combinations maximizing plant performance, in terms of early vigor as in the present study, but also in terms of early vigor impact on final grain yield, in target environments. In the case of rice presented here, preliminary results suggest that higher biomass accumulation would be possible by overcoming the antagonism between early vigor and drought tolerance. 

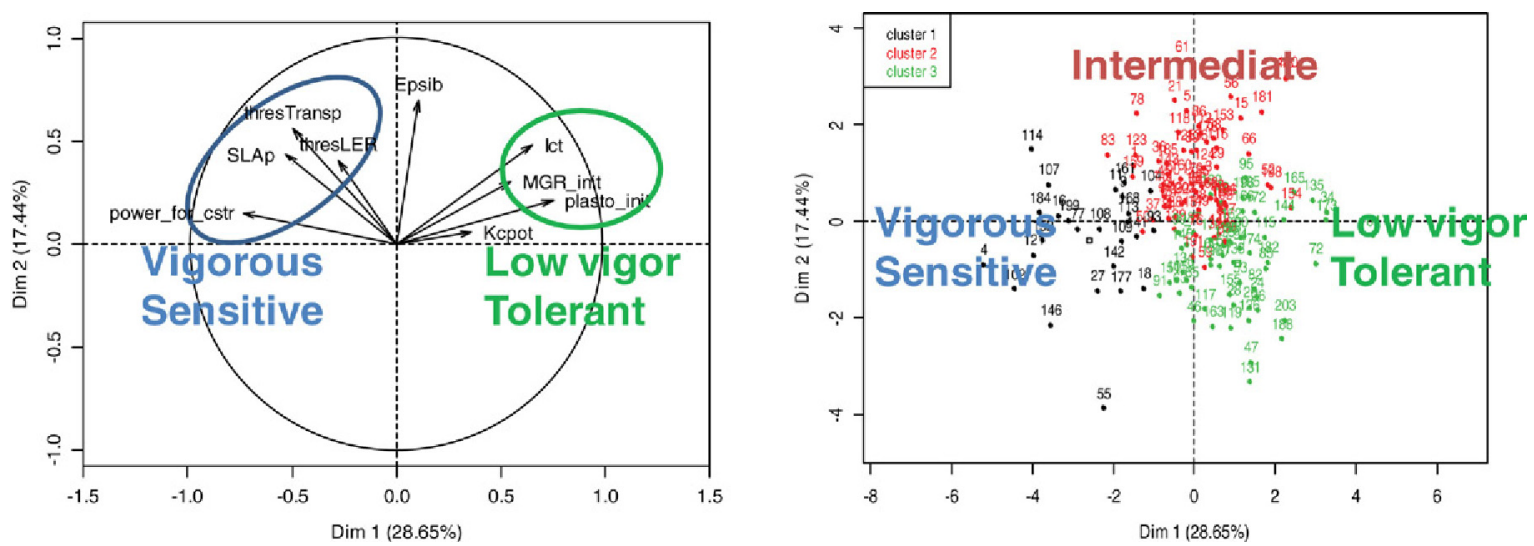

FIG. 14.4 Principal component analysis (PCA) of nine parameters of the ecophysiological model EcoMeristem estimated for 200 genotypes of a rice (Oryza sativa L. ssp. Japonica) diversity panel. Left, projection of the model parameters on the first two axes of the PCA. Right, projection of the genotypes on the first two axes of the PCA. A hierarchical cluster analysis on principal components revealed three groups of genotypes with contrasted early vigor and sensitivity to water deficit. Epsib, light-use efficiency; SLAp, slope of the logarithmic relation between specific leaf area and its rank on a given tiller; power_for_cstr, parameter for reducing Epsib in response to water deficit estimated by $\mathrm{f}$ the fraction of transpirable soil water (FTSW); thresTransp and thresLER, thresholdFTSW at which leaf transpiration and expansion rates, respectively, start decreasing linearly with drying soil; Ict, plant C supply to demand ratio enabling tillering; MGR, meristem growth rate; Kcpot, additive parameter defining the potential length of leaf $n$ depending on the length of leaf $n-1$. Plasto_init, phyllochron $\left({ }^{\circ} \mathrm{Cd}\right)$. Adapted from Luquet et al. (2012a).

place in the F1 generation; (4) most genetic analyses performed do not adequately describe the epistatic and pleiotropic effects of the loci.

\subsection{New technologies and their potential for gene-to-phenotype modeling}

Technological progresses may offer solutions to some of the drawbacks mentioned above. In terms of molecular genetics, Chapter 18 outlines the recent progress in technologies. Briefly, with progress in DNA marker assays and sequencing technologies, it is now feasible to genotype thousands of plants with high densities of markers. In addition, approaches have been developed to analyze the genetic control of quantitative traits, such as association mapping, nested association mapping (e.g. Yu et al., 2006; Brachi et al., 2010) and multiparent advanced generation intercross (MAGIC) populations (Cavanagh et al., 2008).
They potentially address the major limitations of available mapping resources. At the same time, new statistical methods have been developed to detect QTL involved in response curves ('functional mapping'). For example, Ma et al. (2002) combined logistic growth curves and QTL mapping within a mixed model approach, which proved to be powerful to estimate accurately QTL effects and positions (Wu et al., 2002, 2003). Using a similar framework, Malosetti et al. (2006) proposed a non-linear extension of classical mixed models. van Eeuwijk et al. (2010) reviewed advanced statistical methods, e.g. to perform multienvironment and/or multitrait QTL mapping.

In terms of phenotyping, field and controlledconditions platforms (Pieruschka, and Poorter, 2012; White et al., 2012; Fiorani and Schurr, 2013) and networks of field experiments (Hammer et al., 2006; Tardieu and Tuberosa, 2010; Messina 
et al., 2011; Rebetzke et al., 2013) partly answer the need to characterize precisely relevant traits in contrasting environments. Models are also used to identify relevant traits to phenotype (e.g. Reymond et al., 2004; Martre et al., 2007) and to choose field locations or environmental conditions to impose (e.g. Chenu et al., 2013; Chapter 13).

Concerning model development, the strategy to search for physiological processes that are stable across environments has already turned out promising. Incorporating such processes into ecophysiological models that account for interactions at the crop level has been successfully achieved in the APSIM-Maize model with functions describing leaf expansion rate (Fig. 14.2d) that can be linked to QTL effects.

\subsection{Deciphering QTL $\times$ environment interactions}

The understanding of gene/QTL $\times$ E interactions is central to improve fine construction of adapted genotypes. Ecophysiological models have a place of choice to highlight QTL $\times$ E interactions, as they facilitate the interpretation of the $\mathrm{G} \times \mathrm{E}$ interactions through environmental characterization (Chapman, 2008; Chenu et al., 2011; Chapter 13) and are useful to dissect complex traits into component traits with higher heritability (Tardieu and Tuberosa, 2010; van Eeuwijk et al., 2010). In addition, 'gene-to-phenotype' models simulate QTL $\times$ E interactions, and allow interpretation within a genotype-environmentmanagement framework for the target agricultural system. In this direction, Chenu et al. (2009) develop a 'gene-to-phenotype' modeling approach (Fig. 14.2), introducing organ-growth QTL involved in leaf elongation into the APSIMMaize model. Their simulations highlighted the importance of the genetic architecture and $\mathrm{G} \times \mathrm{E}$ interactions when assessing the QTL impact on yield (Chenu et al., 2009) as, for example, QTL could have positive or negative impact on yield depending on the pattern of drought.

\subsection{Link with breeding}

The enormous number of combinations that breeders would ideally analyze to identify bestadapted genotypes highlights a major interest for predictive approaches. Over the last decades, top-down approaches from whole-plant phenotypes to the molecular genomic level (Hammer et al., 2004) have been developed to simulate gene-to-phenotype associations for traits such as plant phenology (e.g. Hoogenboom et al., 2004; Messina et al., 2006) or responses of plant growth and architecture to environment (Tardieu, 2003; Yin et al., 2000; Hammer et al., 2006). While limitations remain, gene-to-phenotype models are being used in breeding (Messina et al., 2011). In addition, robust gene-to-phenotype models linked to quantitative genetics models like QUGENE (Podlich and Cooper, 1998), give new opportunities to explore alternative selection methods and assist breeding for complex traits in broad or specific environments (Chapman et al., 2003).

\section{TOOLS FOR OPTIMIZING TRAIT COMBINATIONS AND MODEL-BASED IDEOTYPING}

To meet the demand for multiobjective attributes, the critical question is how to design best combinations of genetic resources and cultural practices adapted to, and respectful of specific environments. In other terms, the question is 'How to optimize the strong $\mathrm{G} \times \mathrm{E} \times \mathrm{M}$ interactions to design plant ideotypes that meet multicriteria objectives?' This requires integrating two old coexisting visions: the breeder's view of optimizing $G \times E$ interactions, and the agronomist's view doing the same for $\mathrm{G} \times \mathrm{M}$ interactions (Messina et al., 2009). The approach relies on the potentialities of integrating genetic information into ecophysiological models to capture $\mathrm{G} \times \mathrm{E} \times \mathrm{M}$ interactions. The combination of genetic parameters (fingerprint of the genotype), and cultural practices can then be optimized to 
design new genotypes coupled with adequate management, adapted to target environments (e.g. Hammer et al., 2006; Letort et al., 2008).

The design of ideotypes is usually based on antagonistic criteria with respect to strong constraints (biological, economical, ecological, or environmental). The resulting fitness landscapes are often very complex, and researchers initially applied techniques such as trial and error (Haverkort and Grashoff, 2004; Herndl et al., 2007) or sensitivity analysis (Habekotte, 1997) to identify potential ideotypes. The high number of combinations to identify bestadapted genotypes highlights the impossibility of exploring exhaustively the whole $\mathrm{G} \times \mathrm{E} \times \mathrm{M}$ space this way (Messina et al., 2009). Overall, the model-based design of ideotypes is a very difficult non-linear multiobjective optimization problem that resists the classical simulation and optimization methods.

Effective optimization methods have been recently proposed to resolve this problem and bio-inspired optimization algorithms (e.g. genetic algorithms, particle swarm optimization algorithms) are increasingly used for modelbased design of ideotypes (Letort et al., 2008; Qi et al., 2010; Kadrani et al., 2012; Quilot-Turion et al., 2012; Semenov and Stratonovitch, 2013; Semenov et al., 2014), or optimization of management scenarios (Grechi et al., 2012). Multiobjective evolutionary optimization algorithms allow exploration of high-dimension solution spaces in a reasonable computation time. These methods do not require any derivative information and can address the complex multiobjective optimization problems (e.g. very large search spaces, uncertainty, noise, disjoint Pareto curves, etc.) that resist traditional optimization methods. These methods provide the decision maker with a set of diversified solutions with reduced, but sufficient, cardinality. The decision maker will thus have the final choice of the best suited trade-off between criteria and will be provided with the corresponding optimal ideotypes or management practices.
Despite recent advances in the use of optimization methods applied to model-based approaches, their application to plant and crop design and to management is still in its infancy. Some of the studies focused on the optimization of the management scenarios for designing sustainable and integrated production systems, while others dealt with the optimization of morphological or physiological traits taking advantage of complex interactions between traits in different environments. Others stepped further to the optimization of the allelic variations using detailed genetic information allele effects and interactions. Finally, a step further is also to optimize selection strategies to help the creation of optimized genotypes.

\subsection{Optimization of cultural practices}

Ould-Sidi and Lescourret (2011) reviewed model-based design of integrated production systems. They discussed many examples using simulation and optimization techniques and recommended the use of integrative modeling platforms, process-oriented modeling and object/component-oriented techniques to improve the genericity, modularity, and re-use of ecophysiological models and data sharing. They also suggested using ecophysiological models that are spatially explicit and employing multiobjective optimization algorithms based on the Pareto dominance concept.

Two recent studies using a model-based approach coupled with optimization algorithms have to be mentioned because of their relevance to management decisions. Grechi et al. (2012) interfaced a process-based model with a multiobjective optimization algorithm to design new management scenarios in line with integrated production systems objectives. The model describes the interacting peach-aphid dynamics, fruit production and fruit quality, and their control by (1) cultural practices, (2) release of the biological control agent Harmonia axyridis Pallas (Coleptera: Coccinellidae), and (3) insecticide applications. The simulations were 
performed for three virtual farmer profiles differing in the relative importance given to each of the performance criteria. Four pest management strategies namely 'no-treatment', 'conventional' (insecticide-based), 'organic', and 'integrated' were simulated. Simulations showed that agronomic performances were largely explained by cultural practices, while aphid pressure was largely explained by pest control strategies. The scenarios using the 'conventional' pest control strategy were the best, regardless of the farmer profile. However, under the 'no-treatment' strategy (only cultural practices), the resulting scenarios have very good performance except for aphid infestation criterion. Optimal values of cultural management variables displayed a high variability between the farmer production profiles under the 'no-treatment' and 'integrated' strategies, while they were independent of the farmer profile under the 'organic' and 'conventional' strategies.

Wu et al. (2012) proposed an optimal control method for solving a water supply problem for optimal sunflower fruit filling. Using a sunflower ecophysiological model, they compared the numerical solutions, obtained through an iterative optimization gradient-based procedure, and those obtained using genetic algorithms in previous studies (Wu et al., 2005). The authors stated that further improvements in sunflower yield have been found using the optimal control method.

\subsection{Optimization of genetic parameters}

This approach lies in finding combinations of values of the genetic parameters that best satisfy the fixed objectives. Such a set of values would form the 'parametric phenotype' or genotype 'fingerprint' of the ideotype. Only a few studies presented a proof of concept of the approach linking ecophysiological models and optimization methods (Letort et al., 2008; Qi et al., 2010; Quilot-Turion et al., 2012; Semenov and Stratonovitch, 2013; Semenov et al., 2014).
In a theoretical study, Letort et al. (2008) used a particle swarm optimization algorithm to optimize the cob sink strength and the coefficients of the cob sink variation function of the GreenLabMaize to maximize either the cob weight (single objective problem) or both the cob weight and leaf and stem weight (multiobjective problem) for multiusage maize. Their results illustrated the power of such a combined approach to improve the design of ideotypes, especially in case of trade-off between traits. However, a limitation to the use of particle swarm algorithms is their weak exploitation ability and diversity (local search) keeping within the swarm (population of solutions). The consequence is usually a poor choice for the decision maker.

Quilot-Turion et al. (2012) used the Virtual Fruit model (Génard et al., 2010) to design peach genotypes with enhanced fruit quality and resistance to brown rot for given cultural scenarios. They focused on six genetic parameters combined to create the genotypes. Three traits simulated by the model, of major importance for fruit quality and sensitivity to brown rot, were taken into account to evaluate the genotypes. Simulations were performed for four cultural scenarios (two levels of crop load and two water regimens) to analyze the putative impact of cultural practices on the optimized solutions. The authors used NSGA-II (non-dominated sorting genetic algorithm II) with a modified stopping criterion based on the crowding distance (mechanism of diversity control used by the NSGA-II) to speed up the computation (OuldSidi et al., 2012). The modified algorithm obtained solutions similar in quality to those of the original version but after significantly fewer generations. The resulting reduction in computational time for the optimization provides opportunities for further studies (Kadrani et al., 2012, 2013).

The results confirmed the strong antagonism between the criteria considered. Large fruits had a weak sweetness and high crack density and for a given mass, those with improved sweetness had higher crack density. In a current breeding 
scheme, fruit mass would be the only criterion considered but alternative schemes could be considered in the future, favoring organoleptic quality or environment-friendly practices. In those cases, some interesting optimized solutions were identified (Quilot-Turion et al., 2012).

A main weakness of this approach lies in the lack of quantitative relationships between genes and model parameters. It only provides a picture of the optimized space of solutions considering the functioning of the system driven by biophysical constraints only. The suggested solutions represent ideal genotypes the breeder is not sure to be able to create. To produce more realistic genotypes, genetic constraints (e.g. pleiotropic and epistatic effects, gene $\times$ environment interactions) may be integrated to the optimization scheme.

\subsection{Optimization of allelic combinations}

The difficult issue that remains to be solved for a complete optimization of $\mathrm{G} \times \mathrm{E} \times \mathrm{M}$ interactions is the integration in the optimization scheme of the complex genetic architecture controlling the model parameters. Two options can be considered. First, known genetic constraints may be included in the definition of the space of parameter variation to be explored during the optimization. Discontinuous space and links between parameters could be added as constraints of optimization at this step. Then, allelic combinations may be inferred from the parameter values. Letort et al. (2008) tested this option for a virtual maize mapping population built from a simple genetic model (virtual genes and virtual chromosomes). They implemented a genetic algorithm to optimize the allelic combination that maximized cob weight. The use of ecophysiological models to help breeding by optimization has not been stepped over since this theoretical study.

The second option is the direct optimization of allelic combinations. This option requires that genetic information is combined to ecophysio- logical models and may allow consideration of complex genetic models. Some steps have already been made towards this integration and the resulting models are referred to as gene-to-phenotype or QTL-based models (section 3). Chenu et al. (2009) used such a gene-tophenotype model to explore $\mathrm{G} \times \mathrm{E}$ interactions and the complexity of the results highlighted the importance of genetic architecture in the generation of phenotypes (Fig. 14.2). Considerable work is needed to introduce complex genetic architecture in gene-to-phenotype models and to evaluate their predictive capacity against empirical data. However, more than targeting an exact prediction of the phenotypic value of specific genes, these approaches are designed to help understand the dynamic nature of the gene-tophenotype problem and explore genotype-environment systems for defining priorities in model development, trait to focus on, etc.

\subsection{Towards virtual breeding}

To conduct the approach towards its final goal, the next step is to develop a method to optimize the selection schemes necessary to obtain plants as analogous as possible to the ideotypes. The idea is to adjust the selection strategies (e.g. frequency of different alleles in the population, number of selection cycles) in contrasting environments and cultural practices, while considering the genetic diversity and available germplasm. A significant step towards this goal was made by Messina et al. (2011), who developed an integrated method based on round-trip between modeling and experiment. They used the APSIM-Maize model (Keating et al., 2003) coupled to the breeding model QU-GENE (Podlich and Cooper, 1998; Podlich et al., 2004) to reveal interesting trajectories in maize breeding. They included in the model genetic variation for five adaptive traits using an additive genetic model based on three genes and two alleles per locus. Maize phenotypes were simulated for 16 contrasting environments and for 50 years of weather. 
For each environment type and management, reciprocal recurrent selection was simulated using QU-GENE. This study demonstrated the validity of the method to explore the $\mathrm{G} \times \mathrm{E} \times \mathrm{M}$ space, to integrate and apply plant physiology concepts to plant breeding and the value of leveraging this knowledge to develop improved crops. With progress in crop physiology, genomics, genetics, model development and optimization, such integrated approaches are evolving to increase breeding in efficiency.

\section{FUTURE PROSPECTS}

Ecophysiological models are powerful tools to understand $\mathrm{G} \times \mathrm{E} \times \mathrm{M}$ interactions (e.g. Hammer et al., 2010), identify key traits of interest for target environments (e.g. Manschadi et al., 2006; Martre et al., 2007; He et al., 2010; Messina et al., 2011; Veyradier et al., 2013), ease ideotype design (e.g. Quilot-Turion et al., 2012; Semenov and Stratonovitch, 2013) and develop adaptive strategies to cope with climate change (e.g. Asseng et al., 2011; Singh et al., 2012; Zheng et al., 2012; Semenov et al., 2014; Chapter 20).

Preliminary studies reveal the potential of model-based approaches in optimizing allelic combinations of genotypes and cultural practices. This would lead to defining an ideotype adapted to a given environment. Then, based on the available genetic material, a second optimization step (virtual breeding) could help identify better selection strategies leading to new varieties resembling the identified ideotype. This modeling framework has potential to integrate information to predict the potential behavior of a genotype in a given environment under the effect of management practices. Linking such models to multiobjective optimization methods can then be suitable to design innovative ideotypes that would optimize the genotypes and the cultural practices in a given environment (Jeuffroy et al., 2013).

Nevertheless, several scientific and technical challenges need to be overcome, and result- ing ideotypes require experimental test (Andrivon et al., 2013). It appears essential to solve the question of the structure (e.g. interactions between processes in relation to the action of environmental factor on the processes) of ecophysiological models needed to link phenotype and genotype. The domain of validity and realism of the models in terms of modeled processes and their interactions also need further analyses (Rötter et al., 2011; Boote et al., 2013). Compensation of error for processes or interactions between processes (e.g. feedbacks) or parameters that are not taken into account in the model but contribute to the observed phenotype in given environments also need to be solved (Challinor et al., 2014). Moreover considerable efforts are needed to develop robust links between genetic and physiological determinants and the variation of traits relevant to breeders, but we believe that this framework will soon support agronomists and breeders in the definition and creation of improved varieties and sustainable systems that will answer future needs.

\section{References}

Aguirrezábal, L., Martre, P., Pereyra-Irujo, G., Izquierdo, N., Allard, V., 2009. Management and breeding strategies for the improvement of grain and oil quality. In: Sadras, V.O., Calderini, D.F. (Eds.), Crop physiology. Applications for genetic improvement and agronomy. Academic Press, San Diego, pp. 387-421.

Andrivon, D., Giorgetti, C., Baranger, A., et al., 2013. Defining and designing plant architectural ideotypes to control epidemics? Eur. J. Plant Pathol. 135, 611-617.

Asseng, S., Ewert, F., Rosenzweig, C., et al., 2013. Uncertainty in simulating wheat yields under climate change. Nature Clim. Change 3, 827-832.

Asseng, S., Foster, I.A.N., Turner, N.C., 2011. The impact of temperature variability on wheat yields. Glob. Change Biol. 17, 997-1012.

Asseng, S., Turner, N.C., Ray, J.D., Keating, B.A., 2002. A simulation analysis that predicts the influence of physiological traits on the potential yield of wheat. Eur. J. Agron. 17, 123-141.

Bertin, N., Martre, P., Genard, M., Quilot, B., Salon, C., 2010. Under what circumstances can process-based simulation 
models link genotype to phenotype for complex traits? Case study of fruit and grain quality traits. J. Exp. Bot. 61, 955-967.

Boote, K.J., Jones, J.W., Batchelor, W.D., Nafziger, E.D., Myers, O., 2003. Genetic coefficients in the CROPGRO-Soybean model: Links to field performance and genomics. Agron. J. 95, 32-51.

Boote, K.J., Jones, J.W., White, J.W., Asseng, S., Lizaso, J.I., 2013. Putting mechanisms into crop production models. Plant Cell Environ. 36, 1658-1672.

Boote, K.J., Kropff, M.J., Bindraban, P.S., 2001. Physiology and modelling of traits in crop plants: implications for genetic improvement. Agric. Syst. 70, 395-420.

Brachi, B., Faure, N., Horton, M., et al., 2010. Linkage and association mapping of Arabidopsis thaliana flowering time in nature. Plos Genet. 6, e1000940.

Braun, H.J., Pfeiffer, W.H., Pollmer, W.G., 1992. Environments for selecting widely adapted spring wheats. Crop Sci. 22, 1420-1427.

Brisson, N., Gate, P., Gouache, D., Charmet, G., Oury, F.-X., Huard, F., 2010. Why are wheat yields stagnating in Europe? A comprehensive data analysis for France. Field Crops Res. 119, 201-212.

Brunel, S., Teulat-Merah, B., Wagner, M.H., Huguet, T., Prosperi, J.M., Dürr, C., 2009. Using a model-based framework for analysing genetic diversity during germination and heterotrophic growth of Medicago truncatula. Ann Bot. 103, 1103-1117.

Cariboni, J., Gatelli, D., Liska, R., Saltelli, A., 2007. The role of sensitivity analysis in ecological modelling. Ecol. Model. 203, 167-182.

Cavanagh, C., Morell, M., Mackay, I., Powell, W., 2008. From mutations to MAGIC: resources for gene discovery, validation and delivery in crop plants. Curr. Opin. Plant Biol. $11,215-221$.

Ceccarelli, S., 1989. Wide adaptation: how wide? Euphytica 40, 197-205.

Challinor, A., Martre, P., Asseng, A., Ewert, F., Thornton, P.K., 2014. Making the most of climate impacts ensembles. Nat. Clim. Change 4, 77-80.

Chapman, S.C., 2008. Use of crop models to understand genotype by environment interactions for drought in real-world and simulated plant breeding trials. Euphytica 161, 195-208.

Chapman, S., Cooper, M., Podlich, D., Hammer, G., 2003. Evaluating plant breeding strategies by simulating gene action and dryland environment effects. Agron. J. 95, 99-113.

Chenu, K., Chapman, S.C., Hammer, G.L., McLean, G., BenHaj-Salah, H., Tardieu, F., 2008. Short-term responses of leaf growth rate to water deficit scale up to whole-plant and crop levels: an integrated modelling approach in maize. Plant Cell Environ. 31, 378-391.

Chenu, K., Chapman, S., Tardieu, F., McLean, G., Welcker, C., Hammer, G., 2009. Simulating the yield impacts of organ-level quantitative trait loci associated with drought response in maize: a "gene-to-phenotype" modeling approach. Genetics 183, 1507-1523.

Chenu, K., Cooper, M., Hammer, G.L., Mathews, K.L., Dreccer, M.F., Chapman, S.C., 2011. Environment characterization as an aid to wheat improvement: interpreting genotype-environment interactions by modelling waterdeficit patterns in North-Eastern Australia. J. Exp. Bot. 62, 1743-1755.

Chenu, K., Deihimfard, R., Chapman, S.C., 2013. Large-scale characterization of drought pattern: a continent-wide modelling approach applied to the Australian wheatbelt spatial and temporal trends. New Phytol. 198, 801-820.

Chew, Y.H., Wilczek, A.M., Williams, M., Welch, S.M., Schmitt, J., Halliday, K.J., 2012. An augmented Arabidopsis phenology model reveals seasonal temperature control of flowering time. New Phytol. 194, 654-665.

Cilas, C., Bar-Hen, A., Montagnon, C., Godin, C., 2006. Definition of architectural ideotypes for good yield capacity in Coffea canephora. Ann. Bot. 97, 405-411.

Cooper, M., Woodruff, D.R., Phillips, I.G., Basford, K.E., Gilmour, A.R., 2001. Genotype-by-management interactions for grain yield and grain protein concentration of wheat. Field Crops Res. 69, 47-67.

Desanlis, M., Aubertot, J.N., Mestries, E., Debaeke, P., 2013. Analysis of the influence of a sunflower canopy on Phomopsis helianthi epidemics as a function of cropping practices. Field Crops Res. 149, 63-75.

Dingkuhn, M., Luquet, D., Clément-Vidal, A., Tambour, L., Kim, H.K., Song, Y.H., 2007. Is plant growth driven by sink regulation? Implications for crop models, phenotyping approaches and ideotypes. In: Spiertz, J.H.J., Struik, P.C., van Laar, H.H. (Eds.), Scale and complexity in plant systems research: gene-plant-crop relations. Springer, Dordrecht, The Netherlands, pp. 157-170.

Dingkuhn, M., Luquet, D., Quilot, B., de Reffye, P., 2005. Environmental and genetic control of morphogenesis in crops: towards models simulating phenotypic plasticity. Aust. J. Agric. Res. 56, 1289-1302.

Dickmann, D.I., Gold, M.A., Flore, J.A., 1994. The ideotype concept and the genetic improvement of tree crops. Plant Breed. Rev. 12, 163-193.

Donald, C.M., 1968. The breeding of crop ideotype. Euphytica $17,385-403$.

Duvick, D.N., Smith, J.S.C., Cooper, M., 2004. Long-term selection in a commercial hybrid maize breeding program. Plant Breed. Rev. 24, 109-151.

Edmeades, G.O., McMaster, G.S., White, J.W., Campos, H., 2004. Genomics and the physiologist: bridging the gap between genes and crop response. Field Crops Res. 90, 5-18.

Farnsworth, K.D., Niklas, K.J., 1995. Theories of optimization, form and function in branching architecture in plants. Funct. Ecol. 9, 355-363. 
Ferrise, R., Triossi, A., Stratonovitch, P., Bindi, M., Martre, P., 2010. Sowing date and nitrogen fertilisation effects on dry matter and nitrogen dynamics for durum wheat: An experimental and simulation study. Field Crops Res. 117, 245-257.

Fiorani, F., Schurr, U., 2013. Future scenarios for plant phenotyping. Annu. Rev. Plant Biol. 64, 267-291.

Foulkes, M.J., Slafer, G.A., Davies, W.J., et al., 2011. Raising yield potential of wheat. III. Optimizing partitioning to grain while maintaining lodging resistance. J. Exp. Bot. 62, 469-486.

Furbank, R.T., Tester, M., 2011. Phenomics - technologies to relieve the phenotyping bottleneck. Trends Plant Sci. 16, 635-644.

Gaju, O., Allard, V., Martre, P., et al., 2014. Nitrogen partitioning and remobilization in relation to leaf senescence, grain yield and grain nitrogen concentration in wheat cultivars. Field Crops Res. 155, 213-223.

Génard, M., Bertin, N., Borel, C., et al., 2007. Towards a virtual fruit focusing on quality: modelling features and potential uses. J. Exp. Bot. 58, 917-928.

Génard, M., Bertin, N., Gautier, H., Lescourret, F., Quilot, B., 2010. Virtual profiling: a new way to analyse phenotypes. Plant J. 62, 344-355.

Granier, C., Aguirrezabal, L., Chenu, K., et al., 2006. PHENOPSIS, an automated platform for reproducible phenotyping of plant responses to soil water deficit in Arabidopsis thaliana permitted the identification of an accession with low sensitivity to soil water deficit. New Phytol. 169, 623-635.

Grechi, I., Ould-Sidi, M.M., Hilgert, N., Senoussi, R., Sauphanor, B., Lescourret, F., 2012. Designing integrated management scenarios using simulation-based and multi-objective optimization: Application to the peach tree-Myzus persicae aphid system. Ecol. Model. 246, 47-59.

Gutjahr, S., Vaksmann, M., Dingkuhn, M., et al., 2013. Grain, sugar and biomass accumulation in tropical sorghums. I. Trade-offs and effects of phenological plasticity. Funct. Plant Biol. 40, 342-354.

Habekotte, B., 1997. Options for increasing seed yield of winter oilseed rape (Brassica napus L.): a simulation study. Field Crops Res. 54, 109-126.

Hamblin, J., 1993. The ideotype concept: useful or outdated? In: Buxton, D.R., Shibles, R., Forsberg, A. et al. (Eds.), International crop science I. CSSA, Madison, pp. 589-597.

Hammer, G., Cooper, M., Tardieu, F., et al., 2006. Models for navigating biological complexity in breeding improved crop plants. Trends Plant Sci. 11, 587-593.

Hammer, G.L., Dong, Z., McLean, G., et al., 2009. Can changes in canopy and/or root system architecture explain historical maize yield trends in the U.S. corn belt? Crop Sci. 49, 299-312.

Hammer, G.L., Chapman, S., van Oosterom, E., Podlich, D.W., 2005. Trait physiology and crop modelling as a framework to link phenotypic complexity to underlying genetic systems. Aust. J. Agric. Res. 56, 947-960.

Hammer, G.L., Sinclair, T.R., Chapman, S.C., van Oosterom, E., 2004. On systems thinking, systems biology, and the in silico plant. Plant Physiol. 134, 909-911.

Hammer, G.L., van Oosterom, E.J., McLean, G., et al., 2010. Adapting APSIM to model the physiology and genetics of complex adaptive traits in field crops. J. Exp. Bot. 61, 2185-2202.

Hanocq, E., Jeuffroy, M.H., Lejeune-Hénaut, I., Munier-Jolain, N., 2009. Construire des idéotypes pour des systèmes de culture variés en pois d'hiver. Innovat. Agron. 7, 14-28.

Harrison, M.T., Evans, J.R., Dove, H., Moore, A.D., 2011. Dual-purpose cereals: can the relative influences of management and environment on crop recovery and grain yield be dissected? Crop Past. Sci. 62, 930-946.

Haverkort, A.J., Grashoff, C., 2004. IDEOTYPING-POTATO: a modelling approach to genotype performance. In: MacKerron, D.K.L., Haverkort, A.J. (Eds.), Decision support systems in potato production: bringing models to practice. Wageningen Academic Publishers, Wageningen, pp. 198-211.

He, J., Stratonovitch, P., Allard, V., Semenov, M.A., Martre, P., 2010. Global sensitivity analysis of the process-based wheat simulation model SiriusQuality1 identifies key genotypic parameters and unravels parameters interactions. Proc. Soc. Behav. Sci. 2, 7676-7677.

Herndl, M., Shan, C., Wang, P., Graeff, S., Claupein, W., 2007. A model based ideotyping approach for wheat under different environmental conditions in North China plain. Agric. Sci. China 6, 1426-1436.

Hoogenboom, G., White, J.W., 2003. Improving physiological assumptions of simulation models by using genebased approaches. Agron. J. 95, 82-89.

Hoogenboom, G., White, J.W., Messina, R., 2004. From genome to crop: integration through simulation modeling. Field Crops Res. 90, 145-163.

Jeuffroy, M.H., Casadebaig, P., Debaeke, P., Loyce, C., Meynard, J.M., 2013. Agronomic model uses to predict cultivar performance in various environments and cropping systems. A review. Agron. Sustain. Dev. doi: 10.1007/ s13593-013-0170-9.

Kadrani, A., Sidi, M.M.O., Quilot-Turion, B., Génard, M., Lescourret, F., 2012. Particle swarm optimization to design ideotypes for sustainable fruit production systems. Internatl. J. Swarm Intell. Res. 3, 1-19.

Kadrani, A., Ould-Sidi, M.-M., Quilot-Turion, B., Génard, M., Lescourret, F., 2013. Comparison of evolutionary and swarm intelligence-based approaches in the improvement of fruit quality. International Symposium on Operational Research and Applications (ISORAP 2013). Marrakesh, Morocco, May 08-10, 2013.

Karr, J.R., Sanghvi, J.C., Macklin, D.N., et al., 2012. A wholecell computational model predicts phenotype from genotype. Cell 150, 389-401. 
Keurentjes, J.J.B., Angenent, G.C., Dicke, M., et al., 2011. Redefining plant systems biology: from cell to ecosystem. Trends Plant Sci. 16, 183-190.

Keating, B.A., Carberry, P.S., Hammer, G.L., et al., 2003. An overview of APSIM, a model designed for farming systems simulation. Eur. J. Agron. 18, 267-288.

Laperche, A., Devienne-Baret, F., Maury, O., Le Gouis, J., Ney, B., 2006. A simplified conceptual model of carbon/nitrogen functioning for QTL analysis of winter wheat adaptation to nitrogen deficiency. Theor. Appl. Genet. 113, 1131-1146.

Lauri, P.E., Costes, E., 2005. Progress in whole-tree architectural studies for apple cultivar characterization at INRA, France - Contribution to the ideotype approach. Acta Hort. 663, 357-362.

Letort, V., Mahe, P., Cournède, P.H., De Reffye, P., Courtois, B., 2008. Quantitative genetics and functional-structural plant growth models: simulation of quantitative trait loci detection for model parameters and application to potential yield optimization. Ann. Bot. 101, 1243-1254.

Lobell, D.B., Sibley, A., Ortiz-Monasterio, I., 2012. Extreme heat effects on wheat senescence in India. Nat. Clim. Change 2, 186-189.

Luquet, D., Dingkuhn, M., Kim, H.K., Tambour, L., ClémentVidal, A., 2006. EcoMeristem, a model of morphogenesis and competition among sinks in rice. 1. Concept, validation and sensitivity analysis. Funct. Plant Biol. 33, 309-323.

Luquet, D., Rebolledo, M.C., Soulié, J.C., 2012a. Functionalstructural plant modeling to support complex trait phenotyping: Case of rice early vigour and drought tolerance using EcoMeristem model. IEEE International Symposium. 4 (PMA'12). In: Kang, M., Dumont, Y., Guo, Y. (Eds.), Plant growth modeling, simulation, visualization and applications (PMA), 2012 IEEE Fourth International Symposium, Shangai, China, pp. 270-277.

Luquet, D., Soulié, J.C., Rebolledo, M.C., Rouan, L., Clément-Vidal, A., Dingkuhn, M., 2012b. Developmental dynamics and early growth vigour in rice 2 . Modelling genetic diversity using EcoMeristem. J. Agron. Crop Sci. 198, 385-398.

Ma, C.X., Casella, G., Wu, R., 2002. Functional mapping of quantitative trait loci underlying the character process: a theoretical framework. Genetics 161, 1751-1762.

Makowski, D., Naud, C., Jeuffroy, M.H., Barbottin, A., Monod, H., 2006. Global sensitivity analysis for calculating the contribution of genetic parameters to the variance of crop model prediction. Reliab. Eng. Syst. Safe. 91, 1142-1147.

Malosetti, M., Visser, R.G.F., Celis-Gamboa, C., Eeuwijk, F.A., 2006. QTL methodology for response curves on the basis of non-linear mixed models, with an illustration to senescence in potato. Theor. Appl. Genet. 113, 288-300.

Manschadi, A.M., Christopher, J., deVoil, P., Hammer, G.L., 2006. The role of root architectural traits in adaptation of wheat to water-limited environments. Funct. Plant Biol. 33, 823-837.

Marshall, D.R., 1991. Alternative approach and perspectives in breeding for higher yields. Field Crops Res. 26, 171-190.

Martre, P., Jamieson, P.D., Semenov, M.A., Zyskowski, R.F., Porter, J.R., Triboi, E., 2006. Modelling protein content and composition in relation to crop nitrogen dynamics for wheat. Eur. J. Agron. 25, 138-154.

Martre, P., Semenov, M.A., Jamieson, P.D., 2007. Simulation analysis of physiological traits to improve yield, nitrogen use efficiency and grain protein concentration in wheat. In: Spiertz, J.H.J., Struik, P.C., Van Laar, H.H. (Eds.), Scale and complexity in plant systems research, gene-plant-crop relations. Springer, Dordrecht, The Netherlands, pp. 181-201.

Messina, C., Hammer, G.L., Dong, Z., Podlich, D., Cooper, M., 2009. Modelling crop improvement in a $\mathrm{G} \times \mathrm{E} \times \mathrm{M}$ framework via gene-trait-phenotype relationships. In: Sadras, V.O., Calderini, D.F. (Eds.), Crop physiology. Applications for genetic improvement and agronomy. Academic Press, San Diego, pp. 235-265.

Messina, C.D., Jones, J.W., Boote, K.J., Vallejos, C.E., 2006. A gene-based model to simulate soybean development and yield responses to environment. Crop Sci. 46, 456-466.

Messina, C.D., Podlich, D., Dong, Z., Samples, M., Cooper, M., 2011. Yield-trait performance landscapes: from theory to application in breeding maize for drought tolerance. J. Exp. Bot. 62, 855-868.

Mock, J.J., Pearce, R.B., 1975. An ideotype of maize. Euphytica 24, 613-623.

Morris, M.D., 1991. Factorial sampling plans for preliminary computational experiments. Technometrics 33, 161-174.

Ould-Sidi, M.M., Lescourret, F., 2011. Model-based design of integrated production systems: a review. Agron. Sustain. Dev. 31, 571-588.

Ould-Sidi, M.M., Kadrani, A., Quilot-Turion, B., Lescourret, F., Génard, M., 2012. Compromising NSGA-II performances and stopping criteria: case of virtual peach design. The 4th International Conference on Metaheuristics and Nature Inspired Computing (META'2012). October 27-31, 2012, Port Kintaoui, Tunisia.

Oury, F.X., Berard, P., Brancourt-Hulmel, M., et al., 2003. Yield and grain protein concentration in bread wheat: a review and a study of multi-annual data from a French breeding program. J. Genet. Breed. 57, 59-68.

Pedró, A., Savin, R., Slafer, G.A., 2012. Crop productivity as related to single-plant traits at key phenological stages in durum wheat. Field Crops Res. 138, 42-51.

Peng, S., Khush, G.S., Virk, P., Tang, Q., Zou, Y., 2008. Progress in ideotype breeding to increase rice yield potential. Field Crop Res. 108, 32-38.

Pieruschka, R., Poorter, H., 2012. Phenotyping plants: genes, phenes and machines Introduction. Funct. Plant Biol. 39, 813-820. 
Podlich, D., Cooper, M., 1998. QU-GENE: a simulation platform for quantitative analysis of genetic models. Bioinformatics 14, 632-653.

Podlich, D.W., Winkler, C.R., Cooper, M., 2004. Mapping as you go: an effective approach for marker-assisted selection of complex traits. Crop Sci. 44, 1560-1571.

Qi, R., Ma, Y., Hu, B., de Reffye, P., Cournede, P.H., 2010. Optimization of source-sink dynamics in plant growth for ideotype breeding: A case study on maize. Comput. Electron. Agr. 71, 96-105.

Quilot, B., Kervella, J., Génard, M., Lescourret, F., 2005. Analysing the genetic control of peach fruit quality through an ecophysiological model combined with a QTL approach. J. Exp. Bot. 56, 3083-3092.

Quilot-Turion, B., Ould-Sidi, M.M., Kadrani, A., Hilgert, N., Génard, M., Lescourret, F., 2012. Optimization of parameters of the 'Virtual Fruit' model to design peach genotype for sustainable production systems. Eur. J. Agron. 42, 34-48.

Rasmusson, D.C., 1987. An evaluation of ideotype breeding. Crop Sci. 27, 1140-1146.

Rasmusson, D.C., 1991. A plant breeder's experience with ideotype breeding. Field Crops Res. 26, 191-200.

Rebetzke, G.J., Chenu, K., Biddulph, B., et al., 2013. A multisite managed environment facility for targeted trait and germplasm phenotyping. Funct. Plant Biol. 40, 1-13.

Rebolledo, M.C., Dingkuhn, M., Clément-Vidal, A., Rouan, L., Dingkuhn, M., 2012. Phenomics of rice early vigour and drought response: Are sugar related and morphogenetic traits relevant? Rice J. 5, 22.

Rebolledo, M.C., Luquet, D., Courtois, B., et al., 2013. Can early vigour occur in combination with drought tolerance and efficient water use in rice genotypes? Funct. Plant Biol. 40, 582-594.

Reymond, M., Muller, B., Leonardi, A., Charcosset, A., Tardieu, F., 2003. Combining quantitative trait loci analysis and an ecophysiological model to analyze the genetic variability of the responses of maize leaf growth to temperature and water deficit. Plant Physiol. 131, 664-675.

Reymond, M., Muller, B., Tardieu, F., 2004. Dealing with the genotype $x$ environment interaction via a modelling approach: a comparison of QTLs of maize leaf length or width with QTL of model parameters. J. Exp. Bot. 55, 2461-2472.

Reynolds, J.F., Acock, B., 1985. Predicting the response of plants to increasing carbon dioxide: A critique of plant growth models. Ecol. Model. 29, 107-129.

Reynolds, M., Manes, Y., Izanloo, A., Langridge, P., 2009. Phenotyping approaches for physiological breeding and gene discovery in wheat. Ann. Appl. Biol. 155, 309-320.

Reynolds, M.P., Rajaram, S., McNab, A. (Eds.), 1996. Increasing yield potential in wheat: breaking the barriers. Proceedings of a Workshop Held in Ciudad Obregón, Sonora, Mexico, 28-30 Mar. Mexico, DF, CIMMYT.
Richards, R.A., Rebetzke, G.J., Watt, M., Condon, A.G., Spielmeyer, W., Dolferus, R., 2010. Breeding for improved water productivity in temperate cereals: phenotyping, quantitative trait loci, markers and the selection environment. Funct. Plant Biol. 37, 85-97.

Rötter, R.P., Carter, T.R., Olesen, J.E., Porter, J.R., 2011. Cropclimate models need an overhaul. Nat. Clim. Change 1, 175-177.

Sanghvi, J.C., Regot, S., Carrasco, S., et al., 2013. Accelerated discovery via a whole-cell model. Nat. Meth. 10, 1192-1195.

Saltelli, A., Chan, K., Scott, E.M., 2000. Sensitivity analysis. John Wiley and Sons, New York.

Saltelli, A., Tarantola, S., Chan, K.P.-S., 1999. A quantitative model-independent method for global sensitivity analysis of model output. Technometrics 41, 39-56.

Sekhon, S., Mebane, W.R., 2011. Genetic optimization using derivatives: The genoud Package for R. J Stat. Softw. 42, $1-26$.

Sedgley, R.H., 1991. An appraisal of the Donald ideotype after 21 years. Field Crops Res. 26, 93-112.

Semenov, M.A., Stratonovitch, P., 2013. Designing highyielding wheat ideotypes for a changing climate. Food Energ. Secur. 2, 185-196.

Semenov, M.A., Stratonovitch, P., Alghabari, F., Gooding, M.J., 2014. Adapting wheat in Europe for climate change. J. Cer. Sci., http:/ / dx.doi.org/10.1016/j.jcs.2014.01.006.

Shearman, V.J., Sylvester-Bradley, R., Scott, R.K., Foulkes, M.J., 2005. Physiological processes associated with wheat yield progress in the UK. Crop Sci. 45, 175-185.

Sinclair, T.R., Purcell, L.C., Sneller, C.H., 2004. Crop transformation and the challenge to increase yield potential. Trends Plant. Sci. 9, 70-75.

Singh, P., Boote, K.J., Kumar, U., Srinivas, K., Nigam, S.N., Jones, J.W., 2012. Evaluation of genetic traits for improving productivity and adaptation of groundnut to climate change in India. J. Agron. Crop Sci. 198, 399-413.

Socias, R., Felipe, A.J., Gómez Aparisi, J., García, J.E., Dicenta, F., 1998. The ideotype concept in almond. Acta Hort. 470, 51-56.

Tardieu, F., 2003. Virtual plants: modelling as a tool for the genomics of tolerance to water deficit. Trends Plant Sci. 8, 9-14.

Tardieu, F., Tuberosa, R., 2010. Dissection and modelling of abiotic stress tolerance in plants. Curr. Opin. Plant Biol. 13, 206-212.

Tardieu, F., 2012. Any trait or trait-related allele can confer drought tolerance: just design the right drought scenario. J. Exp. Bot. 63, 25-31.

ter Steege, M.W., den Ouden, F.M., Lambers, H., Stam, P., Peeters, A.J., 2005. Genetic and physiological architecture of early vigor in Aegilops tauschii, the D-genome donor of hexaploid wheat. A quantitative trait loci analysis. Plant Physiol. 139, 1078-1094. 
van Eeuwijk, F., Bink, M., Chenu, K., Chapman, S., 2010. Detection and use of QTL for complex traits in multiple environments. Curr. Opin. Plant Biol. 13, 193-205.

Veyradier, M., Christopher, J., Chenu, K., 2013. Quantifying the potential yield benefit of root traits. In: Sievänen, R., Nikinmaa, E., Godin, C., Lintunen, A., Nygren, P. (Eds.), Proceedings of the $7^{\text {th }}$ International Conference on Functional-Structural Plant Models. Saariselkä, Finland, 9-14 June. pp. 317-319.

Welch, S.M., Dong, Z.S., Roe, J.L., Das, S., 2005. Flowering time control: gene network modelling and the link to quantitative genetics. Aust. J. Agric. Res. 56, 919-936.

White, J.W., Andrade-Sanchez, P., Gore, M.A., et al., 2012. Field-based phenomics for plant genetics research. Field Crops Res. 133, 101-112.

Welcker, C., Boussuge, B., Bencivenni, C., Ribaut, J.M., Tardieu, F., 2007. Are source and sink strengths genetically linked in maize plants subjected to water deficit? A QTL study of the responses of leaf growth and of anthesissilking interval to water deficit. J. Exp. Bot. 58, 339-349.

White, J.W., Hoogenboom, G., 1996. Simulating effects of genes for physiological traits in a process-oriented crop model. Agron. J. 88, 416-442.

White, J.W., Hoogenboom, G., 2003. Gene-based approaches to crop simulation: Past experiences and future opportunities. Agron. J. 95, 52-64.

Wu, L., de Reffye, P., Hu, B.G., Le Dimet, F.X., Cournède, P.H., 2005. A water supply optimization problem for plant growth based on GreenLab model. In: Kamgnia, E., Philippe, B., Slimani, Y. (Eds.), 7ème Colloque Africain sur la Recherche en Informatique. Hammamet, Tunisie, novembre 2004. pp. 194-207.
Wu, L., Le Dimet, F.X., de Reffye, P., Hu, B.G., Cournède, P.H., Kang, M.Z., 2012. An optimal control methodology for plant growth - Case study of a water supply problem of sunflower. Math. Comput. Simulat. 82, 909-923.

Wu, R., Ma, C.X., Zhao, W., Casella, G., 2003. Functional mapping for quantitative trait loci governing growth rates: a parametric model. Physiol. Genomics 14, 241-249.

Wu, W., Zhou, Y., Li, W., Mao, D., Chen, Q., 2002. Mapping of quantitative trait loci based on growth models. Theor. Appl. Genet. 105, 1043-1049.

Yin, X., Struik, P.C., 2008. Applying modelling experiences from the past to shape crop systems biology: the need to converge crop physiology and functional genomics. New Phytol. 179, 629-642.

Yin, X., Chasalow, S.C., Dourleijn, C.J., Stam, P., Kropff, M.J., 2000. Coupling estimated effects of QTL for physiological traits to a crop growth model: predicting yield variation among recombinant inbred lines in barley. Heredity 85, 539-549.

Yin, X., Struik, P.C., Tang, J., Qi, C., Liu, T., 2005. Model analysis of flowering phenology in recombinant inbred lines of barley. J. Exp. Bot. 56, 959-965.

Yu, J.M., Pressoir, G., Briggs, W.H., et al., 2006. A unified mixed-model method for association mapping that accounts for multiple levels of relatedness. Nat. Genet. 38, 203-208.

Zheng, B., Chenu, K., Dreccer, M.F., Chapman, S.C., 2012. Breeding for the future: what are the potential impacts of future frost and heat events on sowing and flowering time requirements for Australian bread wheat (Triticum aestivium) varieties? Glob. Change Biol. 18, 2899-2914. 